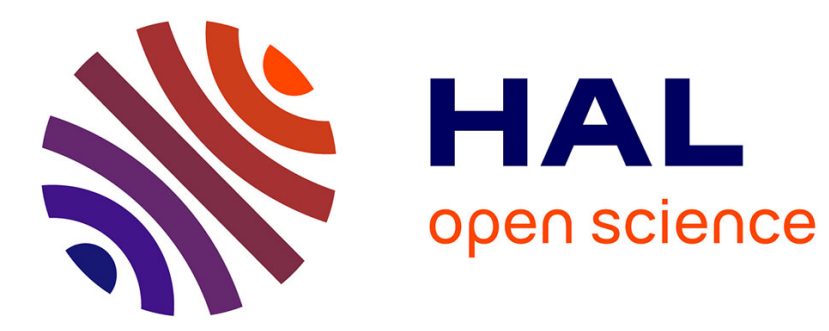

\title{
Intestinal cell-specific vitamin D receptor (VDR)-mediated transcriptional regulation of CYP3A4 gene
}

Petr Pavek, Katerina Pospechova, Lucie Svecova, Zdenka Syrova, Lucie Stejskalova, Jana Blazkova, Zdenek Dvorak, Jaroslav Blahos

\section{To cite this version:}

Petr Pavek, Katerina Pospechova, Lucie Svecova, Zdenka Syrova, Lucie Stejskalova, et al.. Intestinal cell-specific vitamin D receptor (VDR)-mediated transcriptional regulation of CYP3A4 gene. Biochemical Pharmacology, 2009, 79 (2), pp.277. 10.1016/j.bcp.2009.08.017 . hal-00535827

\section{HAL Id: hal-00535827 \\ https://hal.science/hal-00535827}

Submitted on 13 Nov 2010

HAL is a multi-disciplinary open access archive for the deposit and dissemination of scientific research documents, whether they are published or not. The documents may come from teaching and research institutions in France or abroad, or from public or private research centers.
L'archive ouverte pluridisciplinaire HAL, est destinée au dépôt et à la diffusion de documents scientifiques de niveau recherche, publiés ou non, émanant des établissements d'enseignement et de recherche français ou étrangers, des laboratoires publics ou privés. 


\section{Accepted Manuscript}

Title: Intestinal cell-specific vitamin D receptor

(VDR)-mediated transcriptional regulation of CYP3A4 gene

Authors: Petr Pavek, Katerina Pospechova, Lucie Svecova, Zdenka Syrova, Lucie Stejskalova, Jana Blazkova, Zdenek

Dvorak, Jaroslav Blahos

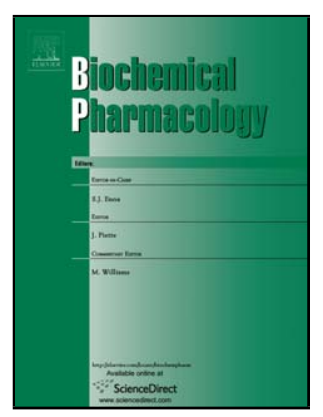

PII: S0006-2952(09)00697-2

DOI: doi:10.1016/j.bcp.2009.08.017

Reference: BCP 10301

To appear in: $\quad B C P$

Received date: $\quad$ 17-7-2009

Revised date: $\quad 16-8-2009$

Accepted date: $\quad$ 17-8-2009

Please cite this article as: Pavek P, Pospechova K, Svecova L, Syrova Z, Stejskalova L, Blazkova J, Dvorak Z, Blahos J, Intestinal cell-specific vitamin D receptor (VDR)mediated transcriptional regulation of CYP3A4 gene, Biochemical Pharmacology (2008), doi:10.1016/j.bcp.2009.08.017

This is a PDF file of an unedited manuscript that has been accepted for publication. As a service to our customers we are providing this early version of the manuscript. The manuscript will undergo copyediting, typesetting, and review of the resulting proof before it is published in its final form. Please note that during the production process errors may be discovered which could affect the content, and all legal disclaimers that apply to the journal pertain. 


\section{Intestinal cell-specific vitamin D receptor (VDR)-mediated transcriptional regulation of CYP3A4 gene}

Petr Pavek* $^{a}$, Katerina Pospechova ${ }^{a}$, Lucie Svecova $^{a}, Z_{\text {denka Syrova }}{ }^{b}$, Lucie Stejskalova $^{a}$, Jana Blazkova $^{c}$, Zdenek Dvorak $^{d}$, Jaroslav Blahos $^{b}$

${ }^{a}$ Department of Pharmacology and Toxicology, Faculty of Pharmacy in Hradec Kralove, Charles University in Prague, Heyrovskeho 1203, Hradec Kralove, CZ-500 05, Czech Republic; ${ }^{b}$ Laboratory of Molecular Pharmacology and ${ }^{c}$ Laboratory of Viral and Cellular Genetics, Institute of Molecular Genetics, Academy of Sciences of the Czech Republic, Vídeňská 1083, Praha 4, CZ-142 20, Czech Republic; and ${ }^{d}$ Department of Cell Biology and Genetics, Faculty of Science, Palacky University in Olomouc, Slechtitelu 11, Olomouc, CZ-783 71, Czech Republic

\section{Corresponding author:}

Petr Pavek PhD., Department of Pharmacology and Toxicology, Charles University in Prague, Faculty of Pharmacy, Heyrovskeho 1203, Hradec Kralove, CZ-500 05, Czech Republic, Tel. +420-495-067-334; Fax.+420-495-067-170; E-mail: petr.pavek@faf.cuni.cz 
Abbreviations: CAR, constitutive androstane receptor; eNR3A4, essential distal nuclear receptor-binding element for CYP3A4 induction; ER6, everted repeat separated by six nucleotides; prER6, ER6 in the CYP3A4 proximal promoter; DR4, direct repeat separated by four nucleotides; PXR, pregnane X receptor; RE, response element; qRT-PCR, quantitative real-time reverse transcriptase polymerase chain reaction; $\mathrm{RXR} \alpha$, retinoid $\mathrm{X}$ receptor $\alpha$ (9-cis retinoic acid receptor- $\alpha$ ); VDR, vitamin D receptor; XREM, xenobiotic responsive enhancer module; CLEM4, constitutive liver enhancer module of CYP3A4; 1,25OHvitD ${ }_{3}, 1 \alpha, 25$ dihydroxyvitamin $\mathrm{D}_{3}$; LCA, lithocholic acid; CDCA, chenodeoxycholic acid; EMSA, electrophoretic mobility shift assay; ChIP; chromatin immunoprecipitation. 


\begin{abstract}
CYP3A4 is the most important drug-metabolizing enzyme that is involved in biotransformation of more than $50 \%$ of drugs. Pregnane $\mathrm{X}$ receptor (PXR) dominantly controls CYP3A4 inducibility in the liver, whereas vitamin D receptor (VDR) transactivates CYP3A4 in the intestine by secondary bile acids. Four major functional PXR-binding response elements of CYP3A4 have been discovered and their cooperation was found to be crucial for maximal up-regulation of the gene in hepatocytes. VDR and PXR recognize similar response element motifs and share DR3(XREM) and proximal ER6 (prER6) response elements of the CYP3A4 gene.
\end{abstract}

In this work, we tested whether the recently discovered PXR response elements DR4(eNR3A4) in the XREM module and the distal ER6 element in the CLEM4 module (CLEM4-ER6) bind VDR/RXR $\alpha$ heterodimer, whether the elements are involved in the intestinal transactivation, and whether their cooperation with other elements is essential for maximal intestinal expression of CYP3A4.

Employing a series of gene reporter plasmids with various combinations of response element mutations transiently transfected into four intestinal cell lines, electrophoretic mobility shift assay (EMSA) and chromatin immunoprecipitation assay (ChIP), we found that the CLEM4-ER6 motif interacts with VDR/RXR $\alpha$ heterodimer and partially cooperates with DR3(XREM) and prER6 in both basal and VDR-mediated inducible CYP3A4 regulation in intestinal cells. In contrast, eNR3A4 is involved only in the basal transactivation in intestinal cells and in the PXR-mediated rifampicin-induced transactivation of CYP3A4 in LS174T intestinal cells.

We thus describe a specific ligand-induced VDR-mediated transactivation of the CYP3A4 gene in intestinal cells that differs PXR-mediated CYP3A4 regulation in hepatocytes. 
Keywords: pharmacokinetics, metabolism, cytochrome P450, CYP3A4, transcriptional 1 regulation, nuclear receptors 


\section{Introduction}

The cytochrome P450 3A4 (CYP3A4) catalyzes the metabolism of more than half of all drugs [1]. Numerous transcription factors and nuclear receptors interacting with multiple promoter/enhancer elements control transcriptional regulation of the human CYP3A4 gene. The CYP3A4 5'-flanking region is $35.8 \mathrm{~kb}$ [2], but only $13 \mathrm{~kb}$ have been systematically analyzed for regulation in hepatocyte or intestinal cells $[3,4]$.

CYP3A4 induction by xenobiotics and hormones is mediated by the pregnane $\mathrm{X}$ receptor (PXR, NR1I2) [5-7], constitutive androstane receptor (CAR, NR1I3) [8, 9], vitamin D receptor (VDR, NR1I1) [10, 11], glucocorticoid receptor- $\alpha$ (GR $\alpha, N R 3 C 1)$ [12], hepatocyte nuclear factor-4 $\alpha(H N F 4 \alpha, N R 2 A 1)$ [13] and retinoid X receptor- $\alpha$ (RXR $\alpha, N R 2 B 1)$ in the liver [3]. In addition, basal (constitutive) CYP3A4 expression in the absence of an inducing agent has been found to correlate with expression of CAR, PXR and HNF4 $\alpha$ in the liver [12, 14].

The drug-induced expression of the CYP3A4 gene in the liver, and to a lesser extent in the intestine, is predominantly regulated through PXR [15]. In contrast, VDR controls CYP3A4 transactivation by the secondary bile acid lithocholic acid (LCA) and subsequent biotransformation of LCA in the intestine $[16,17]$.

Studies on the CYP3A4 gene promoter transactivation via ligand-activated nuclear receptors have uncovered several functional cis-acting response elements (REs) that are common for PXR, CAR and VDR. First, Barwick et al. identified two AG(G/T)TCA hexamers composing an everted repeat separated by six nucleotides (ER6) in the proximal promoter of CYP3A4 (prER6; -169/-152) [18] that was later identified as a PXR binding response element $[5,7,19]$. Goodwin et al. discovered a xenobiotic-responsive enhancer module (XREM) located between -7.8 and $-7.2 \mathrm{~kb}$ upstream of the CYP3A4 transcription start site with a functional DR3 nuclear receptor-binding element 1 (dNR1;-7733/-7719) [6]. Both 
DR3 and prER6 also confer CAR- and VDR-mediated transactivation of the CYP3A4 gene in HepG2 cells $[6,10,20]$.

Matsumura and coworkers discovered that the region from -11.4 to $-10.5 \mathrm{~kb}$, designated a constitutive liver enhancer module of CYP3A4 (CLEM4), is essential for constitutive activation of the CYP3A4 gene in HepG2 cells [21]. Liu and coworkers identified a functional PXR responsive ER6 element localized within the module (CLEM4-ER6 at -11368/-11351) in the Huh7 hepatocarcinoma cell line [22].

Recently, another DR4-type PXR binding cis-element (eNR3A4) in the CYP3A4 gene 5'flanking region (-7618/-7603) was discovered [23].

In addition to individual roles of the REs in CYP3A4 transactivation, positive cooperativity between DR3 and prER6 motifs has been found to be crucial in inducible PXRand CAR-mediated transactivation of CYP3A4 [6, 8]. Moreover, cooperativity among the CLEM4-ER6 motif and DR3/prER6 sites in both basal and inducible transactivation of CYP3A4 has been recently demonstrated to be essential for full CYP3A4 transactivation via PXR in Huh7 cells [22]. Consistently, Drocourt et al. [10] described cooperativity between XREM and the native proximal region $(-262 /+11)$ of the CYP3A4 gene in VDR-mediated transactivation in HepG2 cells.

The role and cooperativity of the response elements in VDR-mediated transactivation have not been systematically studied, however, and it is not known whether the recently discovered eNR3A4 and CLEM4-ER6 motifs interact with the VDR/RXR $\alpha$ heterodimer. Moreover, tissue-specific aspects of VDR-mediated gene regulation and involvement of the REs in the intestinal transactivation of CYP3A4 have not yet been tested.

Accordingly, the aim of this study was to systematically investigate the involvement and cooperativity of the four major response elements prER6, DR3, eNR3A4 and CLEM4-ER6 in the VDR-mediated transactivation of CYP3A4 in model intestinal cell lines. 
Using transient transfection assays with a set of mutated or deleted reporter constructs, electrophoretic mobility shift assay and chromatin immunoprecipitation, we have identified prER6 and DR3 motifs as key cis-acting response elements in the VDR-mediated inducible transactivation of the CYP3A4 gene in several intestinal cell lines. The CLEM4-ER6 motif has rather a modulatory role and the eNR3A4 element has no role in the regulation. We also show that the intestinal VDR-mediated transactivation pattern of the CYP3A4 gene differs from the VDR-mediated transactivation of the gene in the tested hepatocyte-derived cell lines and from the PXR-mediated transactivation in hepatocytes. Our data indicate, moreover, that VDR and PXR cooperatively up-regulate intestinal CYP3A4 transactivation and CYP3A4 mRNA expression in intestinal LS174T cells. 


\section{Material and methods}

\subsection{Cell Lines}

The human colon adenocarcinoma (LS174T, CACO-2), human Caucasian colon carcinoma (HT-29), human ileocecal adenocarcinoma (HCT-8) and human Caucasian hepatocellular carcinoma (HepG2) cell lines were purchased from the European Collection of Cell Cultures (Salisbury, UK) and were used within 20 passages after delivery. The human Mz-Hep-1 hepatocarcinoma cell line was kindly donated by Dr. Ramiro Jover, Unidad de Hepatología Experimental, Hospital La Fe, Valencia, Spain. HepG2, MZ-Hep-1, LS174T, CACO-2 and HT-29 cell lines were maintained in the antibiotic-free Dulbecco's modified Eagle's medium (DMEM) supplemented with 10\% fetal bovine serum (FBS). HCT-8 cell line was cultivated in RPMI 1640 medium supplemented with $1 \mathrm{mM}$ sodium pyruvate and $10 \%$ horse serum. Media for HepG2, CACO-2, HT-29 and LS174T cell lines were supplemented with 1\% nonessential amino acids (NEAA; Sigma-Aldrich, St. Louis, MO). The LS174T human colon adenocarcinoma cell line is one of very few human-derived cell lines with inducible CYP3A4 and relative high expression of PXR [24, 25]. Importantly, all intestinal cell lines used express functional VDR [26-28].

\subsection{Chemicals}

Rifampicin, LCA, CDCA and 1 $\alpha, 25$-dihydroxyvitamin $\mathrm{D}_{3}\left(1,25 \mathrm{OHvitD}_{3}\right)$ and cell culture media were purchased from Sigma-Aldrich (St. Louis, MO). Phenol red-free media were purchased from Invitrogen (Carlsbad, CA). FBS was purchased from PAA (Pasching, Austria). CITCO ((6-(4-chlorophenyl) imidazo [2,1-b][1,3] thiazole-5-carbaldehyde o-(3,4dichlorobenzyl) oxime) was purchased from BIOMOL Research Laboratories (Plymouth Meeting, PA). 
Stock solutions $(1000 \times$ or $3000 \times)$ were prepared in DMSO (Sigma-Aldrich) or in ethanol $\left(1,25 \mathrm{OHvitD}_{3}, 1000 \times\right)$. The final concentration of DMSO in culture media was $0.1 \%(\mathrm{v} / \mathrm{v})$ in all experiments.

\subsection{Plasmids}

The p3A4-luc reporter construct containing the basal promoter $(-361 /+53)$ with the proximal PXR response element (ER6) and the distal xenobiotic responsive enhancer module XREM(-7835/-7208) of the CYP3A4 gene 5'-flanking region inserted to pGL3-Basic reporter vector (Promega, Madison, WI) was described elsewhere [6]. The reporter vector was digested with restriction enzymes and both the proximal promoter sequence $(-361 /+53)$ and the XREM were inserted into the SacI/BglII and BglII/HindIII sites of the pGL4.10 reporter vector (Promega) to generate a p3A4(XREM/prox)-luc reporter plasmid (the plasmid is designated $\mathrm{X}$ in this paper).

To generate the reporter plasmid p(CLEM4-ER6wt)-luc with the CLEM4 region of the CYP3A4 gene [21], the genomic fragment (-11383/-10578, GenBank accession no. AF208107) was generated by PCR using 3A4 -11.4sKpnI as a sense primer and 3A4 10.5 SacI as an antisense primer (Table 1). The fragment was digested with restriction enzymes KpnI and SacI and then inserted into the KpnI/SacI sites of pGL4.23 (Promega). The same fragment was inserted into the $\mathrm{p} 3 \mathrm{~A} 4(\mathrm{XREM} / \mathrm{prox})-$ luc plasmid to generate $\mathrm{p}(3 \mathrm{~A} 4-$ CLEM4/XREM/prox)-luc (the plasmid is designated A).

Mutated reporter plasmids were constructed by the PCR-based site-directed mutagenesis with the QuikChange ${ }^{\circledR}$ Site-Directed Mutagenesis kit (Stratagene, La Jolla, CA) using primers shown in Table 1. The sequences of all constructs were verified by DNA sequencing.

The expression plasmid for PXR (pSG5-hPXR) was kindly provided by Dr. S. Kliewer (University of Texas, Dallas, TX). The human CAR expression plasmid pCR3-hCAR was 
kindly provided by Dr. M. Negishi (National Institute of Environmental Health Sciences, Research Triangle Park, NC). The expression plasmids pSG5-hVDR and pSG5-hRXR $\alpha$ encoding human VDR and RXR $\alpha$ cDNAs were a generous gift from Dr. C. Carlberg (University of Kuopio, Kuopio, Finland). pRL-TK was purchased from Promega.

\subsection{Transient Transfection and Luciferase Gene Reporter Assays}

All transient transfection assays were carried out using Lipofectamine2000 transfection reagent (Invitrogen, Carlsbad, CA) in cells cultivated in the phenol red-free medium containing 10\% charcoal-stripped FCS according to the manufacturer's protocol as described elsewhere [29]. Briefly, cells were seeded into 48-well plates and transfected with a luciferase reporter construct (200 or $250 \mathrm{ng} / \mathrm{well})$, a nuclear receptor expression plasmid (50 ng/well), and the Renilla reniformis luciferase transfection control plasmid (pRL-TK) (30 ng/well) $24 \mathrm{~h}$ later. Cells were maintained in a phenol red-free medium (200 $\mu \mathrm{l})$ supplemented with $10 \%$ charcoal/dextran-stripped FBS with $1,25 \mathrm{OHvitD}_{3}$, rifampicin, CITCO or bile acids at the indicated concentrations for $24 \mathrm{~h}$.

\subsection{Electrophoretic mobility shift assay (EMSA)}

Human VDR, PXR and RXR $\alpha$ were translated in vitro using the TNT Quick Coupled Transcription/Translation System (Promega, Southampton, UK). The EMSA was performed according to the protocol published elsewhere with the 5'-biotinylated probes for ER6CLEM4 and eNR3A4 response elements of the CYP3A4 gene [25]. Oligonucleotide sequences used for EMSA assay are presented in Table 1.

For supershift experiments, $1 \mu \mathrm{g}$ of the anti-RXR $\alpha$ rabbit polyclonal $\mathrm{IgG}$ antibody (sc-553, Santa Cruz Biotechnology, Inc., Santa Cruz, CA) was added to the reaction mixture. 


\subsection{Chromatin immunoprecipitation (ChIP) assay}

LS174T cells were seeded in Petri dishes $\left(13.5 \mathrm{~cm}\right.$ diameter) at the density of $100 \times 10^{3}$ cell $/ \mathrm{cm}^{2}$. After $24 \mathrm{~h}$, the cells were cultured in the presence of ethanol (vehicle) or $1,25 \mathrm{OHvitD}_{3}(10 \mathrm{nM})$ for 4 hours. Chromatin immunoprecipitation assay (ChIP) was performed using the ChIP assay kit (Upstate Biotechnology, Lake Placid, NY) according to the manufacturer's protocol.

Briefly, protein-DNA complexes were cross-linked by adding formaldehyde for $10 \mathrm{~min}$ directly to the medium to final concentration of $1 \%$. Cross-linking was quenched by adding Tris/glycine. Cells were washed twice with phosphate buffered saline (PBS), scraped, resuspended in lysis buffer and sonicated with the BRANSON Digital Sonifier@ S-450D to shear DNA to lengths between 200 and $1000 \mathrm{bp}$. The sonicated cell supernatant was diluted 10-fold in ChIP dilution buffer and after pre-clearing with protein A agarose, 1/18 volume of supernatant was kept as ,input control“ for qPCR analysis. Immunoprecipitation was carried out by incubating the samples $(1.8 \mathrm{~mL})$ overnight at $4^{\circ} \mathrm{C}$ with rotation with the following antibodies (5 $\mu \mathrm{g})$ : rabbit anti-VDR (VDR c-20) (Santa Cruz Biotechnology), rabbit anti-RNA polymerase II (Pol II, N-20, Santa Cruz Biotechnology), anti-acetylated histone H3 and H4 (06-599 and 06-866) (Upstate, Lake Placid, NY) and rabbit IgG (12-370) (Upstate) as a nonspecific IgG control. Protein A agarose beads were then added and incubated for 1 hour. The pellets were gradually washed with buffers. Protein-DNA complexes were then eluted and cross-links were reversed by adding $\mathrm{NaCl}$ during overnight incubation at $65^{\circ} \mathrm{C}$. Proteinase K/RNAase-treated DNA fragments were purified using ChIP DNA Clean \& Concentrator ${ }^{\mathrm{TM}}$ spin column (Zymo Research, Orange, CA). 


\section{7 qPCR Analysis}

The immunoprecipitated DNA fragments of the CYP3A4 promoter and "input samples" were analyzed by TaqMan real-time PCR (qPCR) using primers and TaqMan probes flanking putative VDR binding motifs (Table 1; Fig. 5). PCR was performed in 45 cycles at $94^{\circ} \mathrm{C}$ for $15 \mathrm{~s}$ and $60^{\circ} \mathrm{C}$ for $45 \mathrm{~s}$ and the quantities of PCR products were determined using the Pfaffl's method [30] (for calculation of TaqMan qPCR efficiencies) and employing the SABiosciences Quantitative Real-Time PCR Analysis of Chromatin Immunoprecipitation Manual (http://www.biomol.de/details/SA/chipqpcrmanual.pdf). Data are presented as a relative binding to the non-specific IgG background binding (100\%) of a non-immune rabbit IgG antibody and represent the mean $\pm \mathrm{SD}$ of at least three independent experiments. Triplicate PCRs for each sample were carried out. The threshold cycle $(\mathrm{Ct})$ values for IgG were greater than 35 and less than $0.01 \%$ of the input samples in all experiments.

\section{8 qRT-PCR}

qRT-PCR analyses of CYP3A4 mRNA expression in LS174T cells were performed as described elsewhere [29].

\subsection{Statistical analysis}

The one-way ANOVA followed by the Dunnett's multiple comparison post hoc test or the unpaired Student's $t$ test were used for statistical analyses using GraphPad Prism software (GraphPad Software Inc., San Diego, CA). The two-way ANOVA with interaction was used to analyze the synergistic effect of $1,25 \mathrm{OHvitD}_{3}$ and rifampicin in $\mathrm{LS} 174 \mathrm{~T}$ cells. 


\section{Results}

\subsection{Contribution and cooperation of major response elements in VDR- and PXR-} mediated transactivation of the CYP3A4 gene in the LS174T intestinal cell line

First, we analyzed the relative contribution of the four major known response elements, CLEM4-ER6, DR3, eNR3A4 and prER6, and their cooperativity in the VDR-mediated transactivation of the CYP3A4 gene by $1,25 \mathrm{OHvitD}_{3}$ and LCA in transient transfection experiments in LS174T cells. In parallel, PXR-mediated transactivation was analyzed in the same cell line.

The wild-type $\mathrm{p}(3 \mathrm{~A} 4-\mathrm{CLEM} 4 / \mathrm{XREM} / \mathrm{prox})$-luc reporter construct conferred the highest basal and VDR-mediated inducible luciferase activation (Fig. 1A). Importantly, simultaneous mutations of DR3 and prER6 elements in the context of the wild-type p(3A4CLEM4/XREM/prox)-luc construct (plasmid E) completely abolished the VDR ligandmediated activation in the LS174T cells (Fig. 1A). These data imply that the DR3 and prER6 cis-acting elements are essential and dominantly control VDR-mediated CYP3A4 transactivation in LS174T intestinal cells. On the other hand, these results indicate that the CLEM4-ER6 element alone (or in combination with eNR3A4) does not significantly contribute to the VDR-mediated inducible transactivation of CYP3A4. In agreement, individual disruption of the CLEM4-ER6 motif (plasmid D) had a minor (not statistically significant) effect on 1,25OHvitD 3 -induced VDR-mediated activation of the CYP3A4 reporter construct in LS174T cells (Fig. 1A). In contrast, we found that disruption of the CLEM4-ER6 motif (plasmid D) significantly $(p<0.01)$ suppressed transactivation of the CYP3A4 reporter construct by LCA (Fig. 1A). 
In the next experiments, we examined PXR-mediated transactivation in LS174T cells. We observed that the disruption of all tested response elements abolished the PXR-mediated activation of the CYP3A4 reporter construct (plasmid C, Fig. 1B). Interestingly, we found that rifampicin activated the reporter constructs through all four response elements in a cooperative manner (Fig. 1B, Table 2), whereas LCA is not able to significantly transactivate CYP3A4 reporter constructs if the DR3 element is mutated (plasmids B, C, E, G, H, I; Fig. 1B). Moreover, rifampicin, but not LCA, produced activation of the construct B, thus suggesting involvement of the eNR3A4 element only in rifampicin-induced transactivation under these experimental conditions (Fig. 1B).

\subsection{Contribution and cooperation of major response elements in VDR-mediated transactivation of the CYP3A4 gene in intestinal HCT-8, HT-29 and CACO-2 cell lines}

Consistently with the data reported for the LS174T cells (Fig. 1A), we observed that simultaneous mutations of DR3 and prER6 elements in the context of the wild-type p(3A4CLEM4/XREM/prox)-luc construct (plasmid E) completely abolished the VDR ligandmediated activation of the construct in all tested intestinal cell lines (Fig. 2). These data strongly support the idea that the cooperation of DR3 and prER6 cis-acting elements is critical for the VDR-mediated CYP3A4 regulation in the intestinal cells. Mutation of the CLEM4ER6 response element (plasmid D) had a minor (not statistically significant) effect on $1,25 \mathrm{OHvitD}$-induced reporter construct activation in tested intestinal cell lines (Fig. 2). On the other hand, CLEM4-ER6 element might play a regulatory role and cooperate with DR3 and prER-6 elements in the LCA-induced VDR-mediated intestinal transactivation of CYP3A4, since the individual disruption of the element significantly $(p<0.05)$ decreased the activation of the CYP3A4 reporter construct (plasmid D.; Fig. 2A; see also Fig. 1A). 


\subsection{Contribution and cooperation of major response elements in VDR- and PXR-} mediated transactivation of the CYP3A4 gene in the hepatocyte-derived HepG2 and MZ-Hep-1 cell lines

In HepG2 and MZ-Hep-1 cell lines, simultaneous disruption of DR3 and prER6 elements reduced $>95 \%$ of the $1,25 \mathrm{OHvitD}_{3}$-induced responsiveness of the construct $\mathrm{E}$ (Fig. $3 \mathrm{~A}$ and C). Mutations of the CLEM4-ER6 and eNR3A4 sites diminished the residual inducibility by 1,25OHvitD 3 (plasmid C, Fig. 3A and C). These data demonstrate the central cooperative role of DR3 and prER6 elements and a minor role of CLEM4-ER6 and eNR3A4 elements in the VDR-mediated inducible transactivation of the CYP3A4 gene in the tested cell lines (Table 2).

In the case of PXR, we observed that all four PXR-binding sites together, are essential for the rifampicin-mediated inducible transactivation of the wild-type CYP3A4 luciferase reporter construct in hepatocyte cell lines (Fig. 3B and D; Table 2). In addition, we observed significant $(p<0.05)$ activation of the plasmid $\mathrm{C}$ with mutations in all tested response elements, suggesting the involvement of a yet unknown functional PXR-binding cis-acting element of CYP3A4 gene (Fig. 3B and D).

\footnotetext{
3.4 Role of major response elements in basal transactivation of CYP3A4 in human intestinal and hepatocyte cell lines

Individual disruption of the CLEM4-ER6 motif reduced $40-80 \%$ of the basal luciferase activity in intestinal and hepatocyte cell lines (Fig. 1, 2 and 3; supplementary data). This finding suggests the crucial role of the CLEM4-ER6 element in basal (constitutive) CYP3A4 expression.
}

In agreement with the central role of prER6 element in the ligand-activated transactivation of CYP3A4 in intestinal cells (Table 2), the element was also found to regulate basal 
activation of the wild-type CYP3A4 reporter construct in all of the tested intestinal cell lines (plasmid J, Fig. 1A and B, Fig. 2, supplementary data). The eNR3A4 motifs has a minor role and does not contribute to the baseline CYP3A4 transactivation in any tested cell line with high level of VDR (Table 2, Fig. 1A; Fig. 2; Fig. 3A and C; supplementary data).

\subsection{Role of the CLEM4 module in VDR-mediated transactivation of the CYP3A4} gene

In order to further define the role of the CLEM4 region and the CLEM4-ER6 PXR-binding site in the VDR-mediated transactivation of CYP3A4 in intestinal cells, we generated the reporter construct lacking the CLEM4 region (plasmid X). At the same time, heterologous luciferase reporter plasmids $p$ (CLEM4-ER6wt)-luc and $p$ (CLEM4-ER6mut)-luc were constructed without natural proximal promoter and XREM regions. Deletion of the CLEM4 region from the wild-type $\mathrm{p}(3 \mathrm{~A} 4-\mathrm{CLEM} / \mathrm{XREM} / \mathrm{prox})-$ luc construct significantly reduced the VDR-mediated activation by $1,25 \mathrm{OHvitD}_{3}$ in intestinal LS174T cells (Fig. 4A). Disruption of the CLEM4-ER6 motif (plasmid D) resulted in even more pronounced decrease in activation after $1,25 \mathrm{OHvitD}_{3}$ or rifampicin treatment in $\mathrm{LS} 174 \mathrm{~T}$ cells (Fig. 4A).

In the next experiments, we found that the wild-type p(CLEM4-ER6wt)-luc construct is significantly $(p<0.05)$ transactivated by $1,25 \mathrm{OHvitD}_{3}$ (about 2 -fold activation) and by rifampicin (4-fold activation) in LS174T cells (Fig. 4A). Disruption of CLEM4-ER6 in $\mathrm{p}$ (CLEM4-ER6wt)-luc reduced $1,25 \mathrm{OHvitD}_{3}$-induced activation of the construct by about $60 \%$; the residual activation of p(CLEM4-ER6mut)-luc was not statistically significant (Fig. 4A). Notably, p(CLEM-ER6mut)-luc reporter construct remained responsive to rifampicin treatment and the mutation of CLEM4-ER6 had no significant effect on rifampicin-mediated activation in intestinal LS174T cells, implying presence of a yet unknown PXR-binding site within CLEM4 region (Fig. 4A). 
Next, we examined whether VDR, PXR and CAR transactivate the heterologous luciferase reporter constructs $\mathrm{p}$ (CLEM4-ER6wt)-luc in HepG2 cells (Fig. 4B). We found that $1,25 \mathrm{OHvitD}{ }_{3}$ significantly activates the wild-type construct, but not the CLEM4-ER6 mutated construct (Fig. 4B). In parallel with the data in LS174T cells (Fig. 4A), rifampicin activated both the wild-type and CLEM4-ER6 mutated reporter constructs, although disruption of the ER6 motif suppressed significantly both basal and inducible activities of the mutated reporter plasmid (Fig. 4B). CITCO (500 nM), an agonist of CAR, slightly, but significantly $(p<0.05)$, activated the wild-type, but not the mutated reporter construct, suggesting interaction of $\mathrm{CAR} / \mathrm{RXR} \alpha$ with the ER6 motif in the CLEM4 region (Fig. 4B).

The interactions between VDR/RXR $\alpha$ heterodimer and ER6 and eNR3A4 (DR4) motifs were further examined using EMSA with in vitro-translated VDR and RXR $\alpha$ proteins (Fig. 4C). We found that VDR/RXR $\alpha$ heterodimer binds to the CLEM4-ER6 motif in EMSA experiments in vitro (Fig. 4C.). However, we did not observe any significant interaction of in vitro translated VDR/RXR $\alpha$ heterodimer with eNR3A4 probe (data not shown). On the other hand, we confirmed that $\mathrm{PXR} / \mathrm{RXR} \alpha$ heterodimer binds the element employing EMSA assay (data not shown) [23].

3.6 Recruitment of VDR and RNA polymerase II (PolII), and evaluation of histone $\mathrm{H} 3$ and $\mathrm{H} 4$ acetylation status in the regulatory regions of the CYP3A4 gene after the treatment with $1,25 \mathrm{OHvit} \mathrm{D}_{3}$

LS174T cells were used as a representative cell line for the chromatin immunoprecipitation (ChIP) assay to analyze the recruitment of VDR and PolII as well as changes of histone acetylation in the CYP3A4 gene 5 '-flanking region. Our results indicate that the treatment of 
LS174T cells with $1,25 \mathrm{OHvitD}{ }_{3}$ results in significant $(p<0.05)$ recruitment of VDR to the XREM and proximal promoter regions of the CYP3A4 gene, but not to the CLEM4 module (Fig. 5). Consistently, we observed significantly increased ( $p<0.05$, about 2-fold) histone H3 acetylation within XREM and the proximal promoter, and significantly increased $\mathrm{H} 4$ acetylation within XREM, which is indicative of transcriptional activation at these regulatory regions (Fig. 5.). In contrast, acetylation status of $\mathrm{H} 3$ and $\mathrm{H} 4$ histones in the CLEM4 module was not significantly affected by $1,25 \mathrm{OHvitD}_{3}$ treatment in $\mathrm{LS} 174 \mathrm{~T}$ cells (Fig. 5.).

In next experiments, PolII occupancy of CLEM4 and XREM modules, and of the native proximal promoter of the CYP3A4 gene was analyzed. We observed about 2-fold increase in PolII binding to XREM and proximal promoter regions after $1,25 \mathrm{OHvitD}_{3}$ treatment (Fig. 5); however, the PolII recruitment increase was not statistically different from the vehicle treated cells.

These data well correlate with the proposed dominant roles of DR3 and prER6 motifs in the VDR ligand-induced transactivation of CYP3A4 gene in intestinal cell lines in transient transfection experiments (Fig. 1A, Fig. 2.).

\subsection{VDR and PXR cooperatively up-regulate intestinal CYP3A4 transactivation and CYP3A4 mRNA expression in intestinal LS174T cells.}

Since both DR3 and prER6 responsive elements interact with VDR and PXR in intestinal cells (Fig. 1A, Fig. 2) and both receptors are expressed in the intestine [31], we investigated, whether VDR competes with PXR in the CYP3A4 gene regulation in the intestinal cells. We transfected LS174T cells with the wild-type p(3A4-CLEM4/XREM/prox)-luc construct and either an empty expression vector (control), expression vectors for VDR and PXR or their combinations. We observed that $1,25 \mathrm{OHvitD}_{3}$ and rifampicin individually activates the reporter construct even in the absence of exogenous VDR or PXR cDNA suggesting sufficient 
endogenous activities of VDR and PXR in LS174T cells [25, 27]. Importantly, the combination of $1,25 \mathrm{OHvitD}_{3}$ and rifampicin synergistically increased ( $p<0.05$, Two-way ANOVA) activation of the p(3A4-CLEM4/XREM/prox)-luc construct in LS174T cells (Fig. 6A). If we cotransfected LS174T cell with the reporter plasmid and PXR expression vector, the basal activation of the reporter construct was significantly $(p<0.01)$ boosted by exogenous PXR, but the maximum $1,25 \mathrm{OHvitD}_{3}$-mediated activation was not affected (Fig. 6A). Consequently, inducibility (fold activation) of the construct by $1,25 \mathrm{OHvitD}$ (ligand-induced $^{2}$ activation versus basal activation) was significantly suppressed $(p<0.05)$ in PXR-transfected cells due to the increased basal activation (Fig. 6A). Cotransfection of LS174T cells with the expression vector for VDR did not boost the maximum $1,25 \mathrm{OHvitD}_{3}$-induced activation suggesting high and saturated endogenous VDR activity in LS174T cell line.

In the next experiments, we examined competition of VDR with PXR NRs in the activation of the $\mathrm{p}$ (3A4-CLEM4/XREM/prox)-luc construct in intestinal LS174T cells by lithocholic and chenodeoxycholic acids (Fig. 6B). The primary bile acid chenodeoxycholic acid (CDCA) and the secondary bile acid lithocholic acid are common ligands for VDR [20], FXR [16], and PXR [32, 33]. LCA $(10$ and $50 \mu \mathrm{M})$ significantly activated the reporter construct (4.5- and 9-fold, respectively) in the absence or in the presence of exogenous VDR cDNA, which again demonstrates high endogenous activity of VDR in LS174T cells (Fig. $6 \mathrm{~B})$. On the other hand, CDCA modestly ( 3 -fold, $p<0.05$ ) activated the reporter construct only after cotransfection with FXR (data not shown). Cotransfection of PXR cDNA increased significantly $(p<0.01)$ the basal activation of the reporter construct; however, had no significant effect on maximal activation of the construct by LCA (Fig. 6B). In agreement with the data in panel A, cotransfection of PXR significantly suppressed the LCA-mediated inducibility (fold induction to control) of the reporter construct in LS174T cells due to the 
increase in basal activation (Fig. 6B).

In the next experiments, we investigated the effects of $1,25 \mathrm{OHvit}_{3}, \mathrm{LCA}$ and rifampicin on CYP3A4 mRNA expression in LS174T cells. We found that the combination of $1,25 \mathrm{OHvitD}_{3}$ and rifampicin synergistically $(p<0.05$; Two-way ANOVA) up-regulates CYP3A4 mRNA in comparison with individual effects of $1,25 \mathrm{OHvitD}_{3}$ and rifampicin (Fig. $6 C)$.

Taken together, we detected no competition of VDR and PXR in transactivation of CYP3A4 in intestinal LS174T cells. On the contrary, our data indicate that VDR and PXR ligands could synergistically up-regulate intestinal CYP3A4 transactivation and CYP3A4 mRNA expression. 


\section{Discussion}

In this study, we have identified prER6 and DR3 REs to be crucial for the VDR-mediated inducible transactivation of the CYP3A4 gene in four model intestinal cell lines. On the other hand, we show that the CLEM4-ER6 motif has a minor, and more likely modulatory, role together with DR3 and prER6 REs in the intestinal VDR-mediated CYP3A4 gene expression. The eNR3A4 motif is not involved in the regulation. In contrast, we demonstrate that the eNR3A4 element might be indispensable in basal transactivation of CYP3A4 in both intestinal and liver-derived cells and in rifampicin-induced transactivation in intestinal cells. We thus demonstrate a specific VDR-mediated transactivation pattern of the CYP3A4 gene by VDR ligands $1,25 \mathrm{OHvitD}_{3}$ and LCA in four intestinal cell lines that differs from VDRmediated CYP3A4 transactivation in HepG2 and MZ-Hep-1 hepatocyte cell lines and from PXR-mediated transactivation in human hepatocytes [23]. We also describe an LCA-specific pattern of CYP3A4 transactivation through PXR in the LS174T intestinal cell line, which does not involve the eNR3A4 motif, and an LCA-specific VDR-mediated transactivation in intestinal cells, having a more pronounced role of the CLEM4-ER6 element in the regulation. Finally, we show that VDR and PXR cooperate in transactivation and up-regulation of CYP3A4 mRNA in intestinal LS174T cells.

A number of independent studies have examined the relative contribution of the individual functional PXR/VDR-binding motifs CLEM4-ER6, DR3 (dNR1), prER6 (prPXRE) and eNR3A4 (DR4) in the PXR-mediated transactivation of the CYP3A4 gene. In addition, cooperativity between proximal and distal response elements has been shown to be central for full PXR-, VDR- and CAR-mediated transactivation of CYP3A4 in hepatocytes and hepatocyte-derived cell lines $[6,8,10,22,23]$. Nevertheless, no systematic study on cooperativity of the four major binding sites in both basal and ligand-induced transactivation has yet been reported. In addition, the role of the identified response elements in VDR- 
mediated CYP3A4 transactivation has not been analyzed in the intestinal cells, although it has been shown that VDR plays an important role as an intestinal bile acid receptor that dominantly transactivates intestinal CYP3A4. Recent reports by Matsubara et al. and Makishima et al. [20, 27] clearly demonstrate that LCA, a hydrophobic secondary bile acid that is primarily formed in the intestine by the bacterial $7 \alpha$-dehydroxylation of chenodeoxycholic and ursodeoxycholic acids [34], is a potent VDR agonist and an intestinespecific inducer of the CYP3A4 gene via VDR. Therefore, additional physiological function of VDR has been postulated in the protection against the toxic and carcinogenic effects of the secondary bile acids in the gut [20].

In the present paper, we report that the CLEM4-ER6 response element binds VDR/RXR $\alpha$ heterodimer in vitro in EMSA assay (Fig. 4C). However, disruption of the CLEM4-ER6 motif in the context of the wild-type p(3A4-CLEM4/XREM/prox)-luc CYP3A4 reporter construct had only a minor effect on ligand-induced VDR-mediated activation in intestinal cells (Fig. 1A, Fig. 2). Moreover, the luciferase reporter construct E with the mutated DR3 and prER6 sites is not responsive to VDR ligands in any intestinal cell line (Fig. 1A and 2). Hence, we suggest that the CLEM4-ER6 site has a rather modulatory and cooperative function together with key DR3 and prER6 motifs in intestinal VDR-mediated transactivation of the CYP3A4 gene (Fig. 1A, Fig. 2, Table 2). Supporting that view, we found that the CLEM4-ER6 motif does not significantly recruit VDR after treatment with $1,25 \mathrm{OHvitD}{ }_{3}$ in $\mathrm{LS}_{174 \mathrm{~T}}$ cells in ChIP experiments (Fig. 5). Thus, our data from transient transfection assays using various CYP3A4 gene promoter constructs well correlate with the ChIP data obtained under conditions of native full-length and chromatinized CYP3A4 promoter.

Recently, a novel functional cis-acting PXR-binding element designated eNR3A4 has been discovered to be an essential element for the rifampicin-inducible CYP3A4 transactivation in HepG2 cells, in primary human hepatocytes, and in mice in vivo [23]. Herein, we show that 
the motif has negligible or no effect on CYP3A4 transactivation through VDR (Fig. 1A, Fig. 2). In agreement with this, we observed that only $\operatorname{PXR} / \operatorname{RXR} \alpha$, but not $V D R / R X R \alpha$ heterodimer, binds to the element in EMSA experiments (data not shown). A slight ligandindependent effect of eNR3A4 mutation on the wild-type CYP3A4 reporter construct basal activation in LS174T and to a much lesser extent in HepG2 cells cotransfected with VDR may correlate with substantial endogenous PXR activity in the LS174T cell line (Fig. in supplementary data). We thus suppose that the imperfect DR4-type eNR3A4 motif might be a PXR-specific motif in CYP3A4 transactivation, although the most common VDR binding sites are direct repeats of AGGTCA half-sites separated by three nucleotides (DR3) and $\mathrm{VDR} / \mathrm{RXR} \alpha$ heterodimer can bind even more avidly to a DR4 element [36].

The ligand-activated gene transactivation by the nuclear receptors is dependent on dynamic balance between the coactivators and corepressors. For some nuclear receptors, DNA sitespecific effects on transcription factor activity are linked to response element-specific interactions with corepressors or coactivators. Moreover, the assembly of coactivator complexes is itself a cell-specific process, with signal transduction pathways regulating the composition of specific coactivator complex components by post-translational modifications [35]. Thus, it is reasonable to speculate that the tissue-/cell-specific CYP3A4 transactivation patterns and involvement of REs described in the study is consequence of tissue-specific expression, activation and interaction of coactivators/corepressors with VDR and PXR. In addition, we should consider involvement of tissue-enriched transcription factors such as liver-enriched transcription factors (LEFTs - HNF4 $\alpha, \mathrm{HNF} 1 \alpha, \mathrm{C} / \mathrm{EBP} \alpha$ and $\beta$ etc.) in CYP3A4 transactivation $[3,4,13]$.

In experiments with LCA, we found LCA-specific mechanisms of response elements involvement and cooperation in the PXR- and VDR-mediated CYP3A4 transactivation in the intestinal cells (Fig. 1A, Fig. 2A). In the case of VDR, this observation could be explained 
based on the different recruitment of coactivators to VDR by $1,25 \mathrm{OHvitD}{ }_{3}$ and $\mathrm{LCA}^{\text {[37]. In }}$ support of this, the structure-function relationships of VDR and LCA revealed that LCA interacts with different amino acids in the ligand binding domain (LBD) of VDR in comparison with $1,25 \mathrm{OHvitD}_{3}[38,39]$.

LCA has been shown to interact with nuclear receptors PXR [32, 33], VDR [20] and FXR [16]. Thus, we can suppose an interplay of the nuclear receptors in transactivation of intestinal CYP3A4 by LCA. We therefore analyzed whether VDR and PXR compete in CYP3A4 transactivation in the intestinal cells. We found that VDR and PXR synergistically cooperate in transactivation of the wild-type CYP3A4 reporter construct and in CYP3A4 mRNA upregulation in intestinal LS174T cells (Fig. 6). These findings contrast with the data for hepatocarcinoma HepG2 cells reported by Drocourt an coworkers [10], who reported competition between VDR and PXR and a dominant role of PXR in transactivation of the $\mathrm{p}(3 \mathrm{~A} 4(\mathrm{XREM} /-262 /+11))$-luc reporter construct. We suppose that the synergism of VDR and PXR in the intestinal CYP3A4 regulation could be explained based on the combination of VDR- and PXR-mediated regulation mechanisms in LS174T cells. We propose that in the presence of PXR and VDR ligands all major regulatory motifs of CYP3A4 are activated and simultaneously facilitate transactivation of CY3A4 that results in its full induction.

Interestingly, disruption of the CLEM4-ER6 element did not abolish PXR-mediated transactivation of the reporter construct with the CLEM4 sequence upstream of the minimal promoter $\mathrm{p}$ (CLEM4-ER6mut)-luc (Fig. 4B), suggesting that the CLEM4 module might include another yet undiscovered functional PXR-binding element. This hypothesis corresponds to the data published by Liu et al. [22], who also found significant rifampicinmediated responsiveness of the 3A4-FmutP-luc reporter construct with a mutated CLEM4ER6 motif in Huh7 hepatocarcinoma cells. Consistent with the recent reports [21, 22], we found that the CLEM4-ER6 site dominantly controls basal expression of the CYP3A4 gene in 
liver-derived cells (Table 2; Fig. 3, supplementary data). In addition, we suppose that the motif might also contribute to basal CYP3A4 expression in intestinal cell lines (Table 2; supplementary data).

Although we observed a very consistent pattern of VDR-mediated CYP3A4 transactivation in four model intestinal cell lines and our data well correlate to the data reported for the Huh7 hepatocarcinoma cell line, in primary human hepatocytes or in vivo in C57BL/6 mice [21-23, 27], additional ChIP and gene reporter experiments performed in both primary intestinal cells and in animals, that are beyond the scope of this study, will be needed to further support the conclusions of the study.

In summary, we comprehensively characterize the involvement and cooperativity of major cis-acting response elements in the VDR-mediated intestinal CYP3A4 gene transactivation and describe synergistic interaction of VDR and PXR in transactivation of CYP3A4 in model intestinal cells. 


\section{Acknowledgements}

Authors wish to thank Dr. S. Kliewer, Dr. M. Negishi and Dr. C. Carlberg for providing the PXR, FXR, CAR, VDR and RXR $\alpha$ expression plasmids.

This work was supported by the Czech Scientific Agency (grant no. 303/07/0128 to Petr Pavek), by the project LC 06063 of the Ministry of Education of the Czech Republic (to Jaroslav Blahos) and AV0Z50520514 awarded by the Academy of Sciences of the Czech Republic. 


\section{References}

[1] Li AP, Kaminski DL, Rasmussen A. Substrates of human hepatic cytochrome P450 3A4. Toxicology 1995;104:1-8.

[2] Finta C, Zaphiropoulos PG. The human cytochrome P450 3A locus. Gene evolution by capture of downstream exons. Gene 2000;260:13-23.

[3] Martinez-Jimenez CP, Jover R, Donato MT, Castell JV, Gomez-Lechon MJ. Transcriptional regulation and expression of CYP3A4 in hepatocytes. Curr Drug Metab 2007;8:185-94.

[4] Tegude H, Schnabel A, Zanger UM, Klein K, Eichelbaum M, Burk O. Molecular mechanism of basal CYP3A4 regulation by hepatocyte nuclear factor 4alpha: evidence for direct regulation in the intestine. Drug Metab Dispos 2007;35:946-54.

[5] Bertilsson G, Heidrich J, Svensson K, Asman M, Jendeberg L, Sydow-Backman M, et al. Identification of a human nuclear receptor defines a new signaling pathway for CYP3A induction. Proc Natl Acad Sci U S A 1998;95:12208-13.

[6] Goodwin B, Hodgson E, Liddle C. The orphan human pregnane X receptor mediates the transcriptional activation of CYP3A4 by rifampicin through a distal enhancer module. Mol Pharmacol 1999;56:1329-39.

[7] Lehmann JM, McKee DD, Watson MA, Willson TM, Moore JT, Kliewer SA. The human orphan nuclear receptor PXR is activated by compounds that regulate CYP3A4 gene expression and cause drug interactions. J Clin Invest 1998;102:1016-23.

[8] Goodwin B, Hodgson E, D'Costa DJ, Robertson GR, Liddle C. Transcriptional regulation of the human CYP3A4 gene by the constitutive androstane receptor. Mol Pharmacol 2002;62:359-65. 
[9] Xie W, Barwick JL, Simon CM, Pierce AM, Safe S, Blumberg B, et al. Reciprocal activation of xenobiotic response genes by nuclear receptors SXR/PXR and CAR. Genes Dev 2000;14:3014-23.

[10] Drocourt L, Ourlin JC, Pascussi JM, Maurel P, Vilarem MJ. Expression of CYP3A4, CYP2B6, and CYP2C9 is regulated by the vitamin D receptor pathway in primary human hepatocytes. J Biol Chem 2002;277:25125-32.

[11] Thummel KE, Brimer C, Yasuda K, Thottassery J, Senn T, Lin Y, et al. Transcriptional control of intestinal cytochrome P-4503A by 1alpha,25-dihydroxy vitamin D3. Mol Pharmacol 2001;60:1399-406.

[12] Pascussi JM, Drocourt L, Gerbal-Chaloin S, Fabre JM, Maurel P, Vilarem MJ. Dual effect of dexamethasone on CYP3A4 gene expression in human hepatocytes. Sequential role of glucocorticoid receptor and pregnane X receptor. Eur J Biochem 2001;268:6346-58.

[13] Tirona RG, Lee W, Leake BF, Lan LB, Cline CB, Lamba V, et al. The orphan nuclear receptor HNF4alpha determines PXR- and CAR-mediated xenobiotic induction of CYP3A4. Nat Med 2003;9:220-4.

[14] Wolbold R, Klein K, Burk O, Nussler AK, Neuhaus P, Eichelbaum M, et al. Sex is a major determinant of CYP3A4 expression in human liver. Hepatology 2003;38:97888.

[15] Lin JH. CYP induction-mediated drug interactions: in vitro assessment and clinical implications. Pharm Res 2006;23:1089-116.

[16] Makishima M, Okamoto AY, Repa JJ, Tu H, Learned RM, Luk A, et al. Identification of a nuclear receptor for bile acids. Science 1999;284:1362-5. 
[17] Pavek P, Dvorak Z. Xenobiotic-induced transcriptional regulation of xenobiotic metabolizing enzymes of the cytochrome P450 superfamily in human extrahepatic tissues. Curr Drug Metab 2008;9:129-43.

[18] Barwick JL, Quattrochi LC, Mills AS, Potenza C, Tukey RH, Guzelian PS. Transspecies gene transfer for analysis of glucocorticoid-inducible transcriptional activation of transiently expressed human CYP3A4 and rabbit CYP3A6 in primary cultures of adult rat and rabbit hepatocytes. Mol Pharmacol 1996;50:10-6.

[19] Blumberg B, Sabbagh W, Jr., Juguilon H, Bolado J, Jr., van Meter CM, Ong ES, et al. SXR, a novel steroid and xenobiotic-sensing nuclear receptor. Genes Dev $1998 ; 12: 3195-205$.

[20] Makishima M, Lu TT, Xie W, Whitfield GK, Domoto H, Evans RM, et al. Vitamin D receptor as an intestinal bile acid sensor. Science 2002;296:1313-6.

[21] Matsumura K, Saito T, Takahashi Y, Ozeki T, Kiyotani K, Fujieda M, et al. Identification of a novel polymorphic enhancer of the human CYP3A4 gene. Mol Pharmacol 2004;65:326-34.

[22] Liu FJ, Song X, Yang D, Deng R, Yan B. The far and distal enhancers in the CYP3A4 gene co-ordinate the proximal promoter in responding similarly to the pregnane $\mathrm{X}$ receptor but differentially to hepatocyte nuclear factor-4alpha. Biochem $\mathrm{J}$ 2008;409:243-50.

[23] Toriyabe T, Nagata K, Takada T, Aratsu Y, Matsubara T, Yoshinari K, et al. Unveiling a new essential cis-element for the transactivation of the CYP3A4 gene by xenobiotics. Mol Pharmacol 2008.

[24] Burk O, Arnold KA, Nussler AK, Schaeffeler E, Efimova E, Avery BA, et al. Antimalarial artemisinin drugs induce cytochrome P450 and MDR1 expression by 
[25] Cerveny L, Svecova L, Anzenbacherova E, Vrzal R, Staud F, Dvorak Z, et al. Valproic acid induces CYP3A4 and MDR1 gene expression by activation of constitutive androstane receptor and pregnane $\mathrm{X}$ receptor pathways. Drug Metab Dispos 2007;35:1032-41.

[26] Cui M, Klopot A, Jiang Y, Fleet JC. The effect of differentiation on 1,25 dihydroxyvitamin D-mediated gene expression in the enterocyte-like cell line, Caco-2. J Cell Physiol 2009;218:113-21.

[27] Matsubara T, Yoshinari K, Aoyama K, Sugawara M, Sekiya Y, Nagata K, et al. Role of vitamin D receptor in the lithocholic acid-mediated CYP3A induction in vitro and in vivo. Drug Metab Dispos 2008;36:2058-63.

[28] Thompson PD, Jurutka PW, Whitfield GK, Myskowski SM, Eichhorst KR, Dominguez CE, et al. Liganded VDR induces CYP3A4 in small intestinal and colon cancer cells via DR3 and ER6 vitamin D responsive elements. Biochem Biophys Res Commun 2002;299:730-8.

[29] Svecova L, Vrzal R, Burysek L, Anzenbacherova E, Cerveny L, Grim J, et al. Azole antimycotics differentially affect rifampicin-induced pregnane $\mathrm{X}$ receptor-mediated CYP3A4 gene expression. Drug Metab Dispos 2008;36:339-48.

[30] Pfaffl MW. A new mathematical model for relative quantification in real-time RTPCR. Nucleic Acids Res 2001;29:e45.

[31] Berger U, Wilson P, McClelland RA, Colston K, Haussler MR, Pike JW, et al. Immunocytochemical detection of 1,25-dihydroxyvitamin D receptors in normal human tissues. J Clin Endocrinol Metab 1988;67:607-13. 
[32] Xie W, Radominska-Pandya A, Shi Y, Simon CM, Nelson MC, Ong ES, et al. An essential role for nuclear receptors SXR/PXR in detoxification of cholestatic bile acids. Proc Natl Acad Sci U S A 2001;98:3375-80.

[33] Staudinger JL, Goodwin B, Jones SA, Hawkins-Brown D, MacKenzie KI, LaTour A, et al. The nuclear receptor PXR is a lithocholic acid sensor that protects against liver toxicity. Proc Natl Acad Sci U S A 2001;98:3369-74.

[34] Hofmann AF. Detoxification of lithocholic acid, a toxic bile acid: relevance to drug hepatotoxicity. Drug metabolism reviews 2004;36:703-22.

[35] Rosenfeld MG, Lunyak VV, Glass CK. Sensors and signals: a coactivator/corepressor/epigenetic code for integrating signal-dependent programs of transcriptional response. Genes Dev 2006;20:1405-28.

[36] Quack M, Carlberg C. Ligand-triggered stabilization of vitamin D receptor/retinoid X receptor heterodimer conformations on DR4-type response elements. Journal of molecular biology 2000;296:743-56.

[37] Jurutka PW, Thompson PD, Whitfield GK, Eichhorst KR, Hall N, Dominguez CE, et al. Molecular and functional comparison of 1,25-dihydroxyvitamin $\mathrm{D}(3)$ and the novel vitamin D receptor ligand, lithocholic acid, in activating transcription of cytochrome P450 3A4. Journal of cellular biochemistry 2005;94:917-43.

[38] Adachi R, Shulman AI, Yamamoto K, Shimomura I, Yamada S, Mangelsdorf DJ, et al. Structural determinants for vitamin $\mathrm{D}$ receptor response to endocrine and xenobiotic signals. Mol Endocrinol 2004; 18:43-52.

[39] Choi M, Yamamoto K, Itoh T, Makishima M, Mangelsdorf DJ, Moras D, et al. Interaction between vitamin $\mathrm{D}$ receptor and vitamin $\mathrm{D}$ ligands: two-dimensional alanine scanning mutational analysis. Chemistry \& biology 2003;10:261-70. 
1

2

3

4

5

6

7

8

9

10

11

12

13

14

15

16

17

18

19

20

21

22

23

24

25

26

27

28

29

30

31

32

33

34

35

36

37

38

39

40

41

42

43

44

45

46

47

48

49

50

51

52

53

54

55

56

57

58

59

60

61

62

63

64

65

\section{Footnotes}

* Corresponding author 


\section{Legends for Figures}

Fig. 1. Involvement and cooperativity of major VDR and PXR response elements in transcriptional regulation of the CYP3A4 gene in the human intestinal LS174T cell line. Transactivation of the wild-type CYP3A4 luciferase reporter gene construct and its mutants was examined in transiently transfected intestinal LS174T cells co-transfected with pSG5hVDR (A.) or pSG5-hPXR (B.) expression vectors. pRL-TK control plasmid was used for transfection normalization. Transfected cells were maintained in a medium containing $1,25 \mathrm{OHvitD}{ }_{3}(10 \mathrm{nM})$, lithocholic acid (LCA, $\left.50 \mu \mathrm{M}\right)$ or rifampicin $(10 \mu \mathrm{M})$ for $24 \mathrm{~h}$. After incubation, the cells were lysed and analyzed for both firefly and Renilla luciferase activities. Firefly luciferase activity was normalized to Renilla activity and expressed as fold activation of vehicle-treated cells transfected with the wild-type construct (A). All means \pm S.D. were calculated from quadruplicates of a representative experiment. ${ }^{*} p<0.05,{ }^{* *} p<0.01 \quad-$ statistically different from the vehicle-treated cells transfected with the same luciferase reporter construct. Numbers indicate fold induction to vehicle-treated cells transfected with the same construct. ${ }^{\S} p<0.01$ - statistically different from the LCA-treated cells transfected with the wild-type construct (A). N.S. - not statistically significant.

Fig. 2. Involvement and cooperativity of major response elements in transcriptional regulation of the CYP3A4 gene through VDR nuclear receptor in human intestinal HCT-8, HT-29 and CACO-2 cell lines. Transactivation of the wild-type CYP3A4 luciferase reporter gene construct and its mutants was examined in transiently transfected intestinal HCT-8 (A.), HT-29 (B.) and CACO-2 (C.) cell lines co-transfected with pSG5-hVDR expression vector. pRL-TK control plasmid was used for transfection normalization. Transfected cells were maintained in a medium containing $1,25 \mathrm{OHvitD}_{3}(10 \mathrm{nM})$ or lithocholic acid (LCA, $50 \mu \mathrm{M})$ for $24 \mathrm{~h}$. After incubation, the cells were lysed and analyzed 
for both firefly and Renilla luciferase activities. Firefly luciferase activity was normalized to Renilla activity and expressed as fold activation of vehicle-treated cells transfected with the wild-type construct (A). All means \pm S.D. were calculated from quadruplicates of a representative experiment. ${ }^{*} p<0.05$ - statistically different from the vehicle-treated cells transfected with the same luciferase reporter construct. ${ }^{\S} p<0.05$ - statistically different from the LCA-treated cells transfected with the wild-type construct (A). N.S. - not statistically significant.

Fig. 3. Involvement and cooperativity of major response elements in transcriptional regulation of the CYP3A4 gene through VDR and PXR nuclear receptors in the human hepatocyte-derived HepG2 and MZ-Hep-1 cell lines. Transactivation of the wild-type CYP3A4 luciferase reporter gene construct and its mutants was examined in transiently transfected HepG2 (A.,B.) and MZ-Hep-1 (C.,D.) cell lines co-transfected with pSG5-hVDR (A.,C.) or pSG5-hPXR (B.,D.) expression vectors. pRL-TK control plasmid was used for transfection normalization. Transfected cells were maintained in a medium containing $1,25 \mathrm{OHvitD}_{3}(10 \mathrm{nM})$ or rifampicin $(10 \mu \mathrm{M})$ for $24 \mathrm{~h}$. After incubation, the cells were lysed and analyzed for both firefly and Renilla luciferase activities. Firefly luciferase activity was normalized to Renilla activity and expressed as fold activation of vehicle-treated cells transfected with the wild-type construct A. All means \pm S.D. were calculated from quadruplicates of a representative experiment. ${ }^{*} p<0.05,{ }^{* *} p<0.01$ - statistically different from the vehicle-treated cells transfected with the same luciferase reporter construct. N.S.- not statistically significant.

Fig. 4. Involvement of CLEM4 in transcriptional regulation of the CYP3A4 gene via VDR and PXR nuclear receptors in the intestinal LS174T and HepG2 cell lines. 
Transactivation of the wild-type and mutated CYP3A4 luciferase reporter plasmids was examined in transiently transfected intestinal LS174T (A.) or HepG2 (B.) cells co-transfected with pSG5-hVDR, pSG5-hPXR or pCR3-hCAR expression vectors and treated with either $1,25 \mathrm{OHvitD}_{3}(10 \mathrm{nM})$, rifampicin $(10 \mu \mathrm{M})$ or CITCO $(0.5 \mu \mathrm{M}$, an agonist of hCAR) for $24 \mathrm{~h}$. Data are expressed as fold activation of vehicle-treated cells transfected with the wild-type reporter construct A or $\mathrm{p}$ (CLEM4-ER6wt)-luc plasmid and co-transfected with the appropriate expression vector. All means \pm S.D. were calculated from quadruplicates of a representative experiment and analyzed using ANOVA followed by Dunnett's test. ${ }^{*} p<0.05$; ${ }^{* *} p<0.01 ; * * * p<0.001-$ statistically different from vehicle-treated cells co-transfected the same luciferase reporter and nuclear receptor expression constructs. C. Electrophoretic mobility shift assay (EMSA) with in vitro translated VDR/RXR $\alpha$ proteins was performed with the 5'-biotinylated probes for the ER6-CLEM4 motif as described under Material and Methods. VDR/RXR $\alpha$ complex in the reaction mixture was incubated with $1,25 \mathrm{OHvitD}_{3}(10$ $\mathrm{nM}$ ) for $30 \mathrm{~min}$. For supershift experiments, $1 \mu \mathrm{g}$ of the anti-RXR $\alpha$ rabbit polyclonal $\mathrm{IgG}$ antibody was added to the reaction mixture. Unlabelled double-stranded probe was used as a competitor $(100 \times)$.

Fig. 5. Recruitments of VDR and RNA Polymerase II (PolII) and changes of histone acetylation in the CYP3A4 gene regulatory regions in response to $1,250 H v i t D_{3}$ treatment in LS174T cells. Chromatin immunoprecipitation (ChIP) assay was performed to analyze the association of VDR and changes of histone $\mathrm{H} 3$ and $\mathrm{H} 4$ acetylation within the major regulatory modules of the CYP3A4 gene. Immunoprecipitated DNA fragments extracted from LS174T cells treated with $10 \mathrm{nM} 1,25 \mathrm{OHvitD}$ for $4 \mathrm{~h}$ were analyzed by qPCR with specific primer pairs and TaqMan probes that detect the individual regions of the CYP3A4 gene promoter (shown in upper panel). Data are presented as a relative binding to 
the nonspecific signal of a non-immune rabbit IgG antibody (100\%) and are presented as the mean \pm SD of at least three independent experiments. ${ }^{*} p<0.05$ - statistically different from vehicle-treated cells.

\section{Fig. 6. VDR and PXR cooperatively up-regulate intestinal CYP3A4 transactivation and} CYP3A4 mRNA expression in intestinal LS174T cells. (A.) Transactivation of the wildtype CYP3A4 luciferase reporter plasmid (construct A) in LS174T cells cotransfected with either VDR or PXR expression vector or their combinations and treated with $1,25 \mathrm{OHvitD}_{3}$ $(10 \mathrm{nM})$ or rifampicin (Rif, $10 \mu \mathrm{M})$ for $24 \mathrm{~h}$. (B.) Transactivation of the wild-type CYP3A4 luciferase reporter plasmid in LS174T cells cotransfected with VDR and PXR nuclear receptor expression plasmids and treated with lithocholic acid (LCA)(10 or $50 \mu \mathrm{M})$ or with secondary bile acid chenodeoxycholic acid (CDCA) $(50 \mu \mathrm{M})$ for $24 \mathrm{~h}$. After incubation with the tested compounds, the cells were lysed and analyzed for both firefly and Renilla luciferase activities as described under Material and Methods. Data are expressed as fold activation over vehicle-treated and an empty expression vector (mock)-transfected cells (control). All means \pm S.D. were calculated from quadruplicates of a representative experiment and analyzed using ANOVA followed by Dunnett's test. ${ }^{*} p<0.05 ;{ }^{* *} p<0.01 ;^{* * *} p<0.001 \quad$ - statistically different from vehicle-treated cells co-transfected with the same expression vector or combination of expression vectors; ${ }^{\neq} p<0.01$ - statistically different from vehicle-treated mock-transfected cells (control); ${ }^{\#} p<0.05$ - statistically significant synergism of $1,25 \mathrm{OHvitD}_{3}$ and rifampicin in the CYP3A4 reporter construct activation (Two-way ANOVA); ${ }^{\S} p<0.05$ - statistically significant suppression of a ligand-mediated inducibility (fold activation) in comparison with the effect of the same compound in mock-transfected cells.

C. qRT-PCR analysis of CYP3A4 mRNA expression in intestinal LS174T cells after treatment with $1,25 \mathrm{OHvitD}_{3}$ and rifampicin. LS174T cells were exposed to $10 \mathrm{nM}$ 
$1,25 \mathrm{OHvitD}_{3}, 50 \mu \mathrm{M}$ lithocholic acid (LCA), rifampicin (Rif, $10 \mu \mathrm{M}$ ) or the combination of $1,25 \mathrm{OHvitD} \mathrm{D}_{3}$ and rifampicin for $24 \mathrm{~h}$. mRNA expression of CYP3A4 gene was determined using real-time qRT-PCR and normalized to a HPRT housekeeping gene. The effect of the tested compounds on mRNA expression is presented as fold induction to control vehicletreated cells. Data are presented as the means \pm S.D. of three individual cell samples. ${ }^{* *} p<0.01 ;{ }^{* * *} p<0.001$ - statistically different from vehicle-treated cells; ${ }^{*} p<0.05$ - statistically significant synergism of $1,25 \mathrm{OHvitD}_{3}$ and rifampicin in the CYP3A4 mRNA induction (Twoway ANOVA). 


\section{VDR-mediated transactivation of CYP3A4 in intestinal LS174T cells}
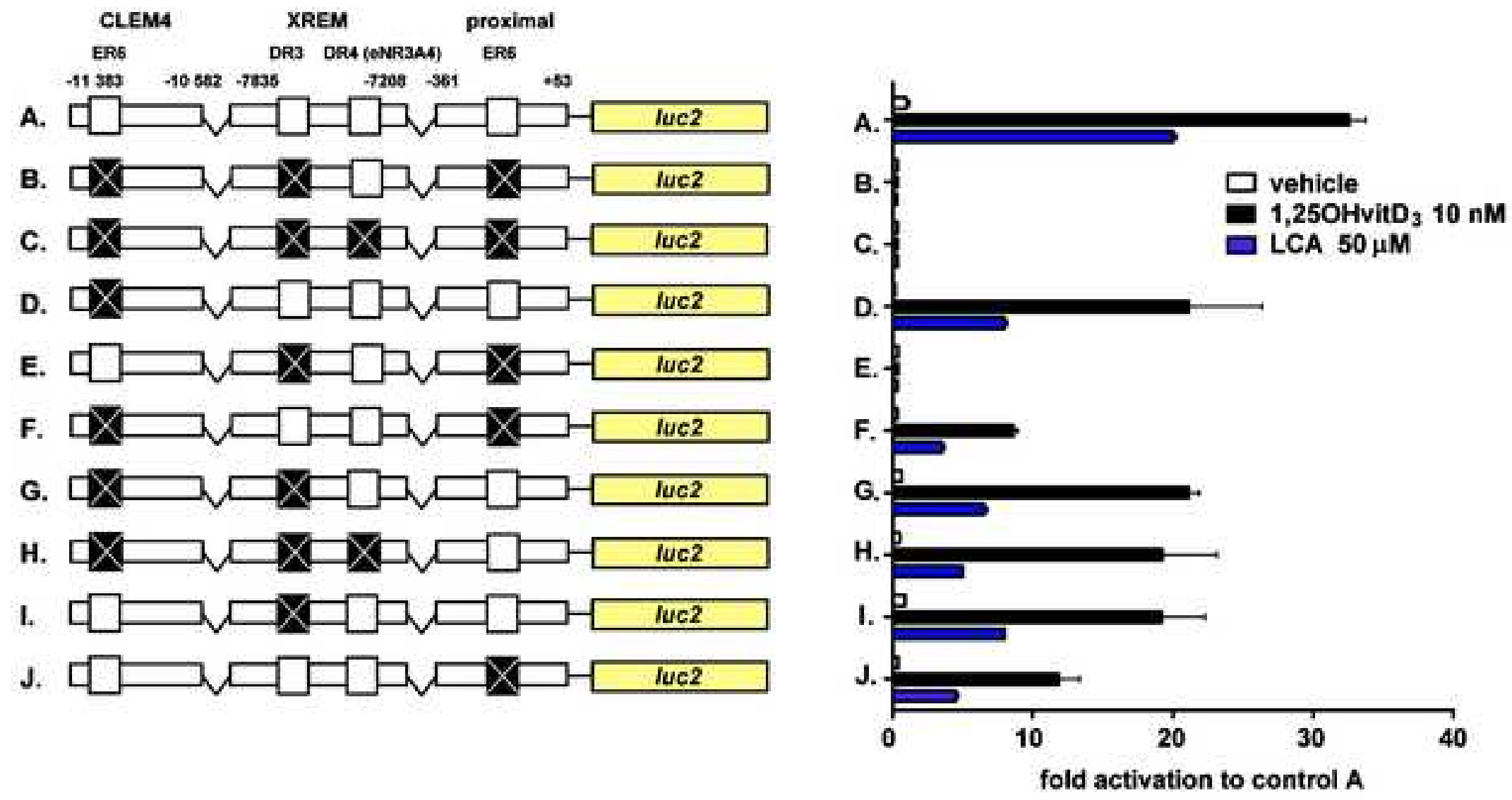
Table1. Sequences of primers, probes and oligonucleotides*.

\section{PCR}

$3 \mathrm{~A} 4-11.4 \mathrm{sKpnI}$

3A4 -10.5SacI

\section{Mutagenesis}

prER6 mut forward prER6mut reverse DR3(XREM)mut forward DR3(XREM)mut reverse CLEM4(ER6)mut forward CLEM4(ER6)mut reverse eNR3A4mut $\alpha$ forward eNR3A4mut $\alpha$ reverse

\section{ChIP}

CYP3A4 CLEM4 region

\section{Forward}

Reverse

Probe BHQ1-FAM

CYP3A4 XREM region

Forward

Reverse

Probe BHQ1-FAM

CYP3A4 proximal promote

Forward

Reverse

Probe BHQ1-FAM

\section{EMSA}

eNR3A4 forward eNR3A4 reverse ER6 (CLEM4) forward ER6 (CLEM4) reverse

\section{5'-CTTGGTAC/CGTAGTCGTTAGAATCTGAAC-3' \\ 5'-AGCTCCTTTGGGAGGGAAA-3'}

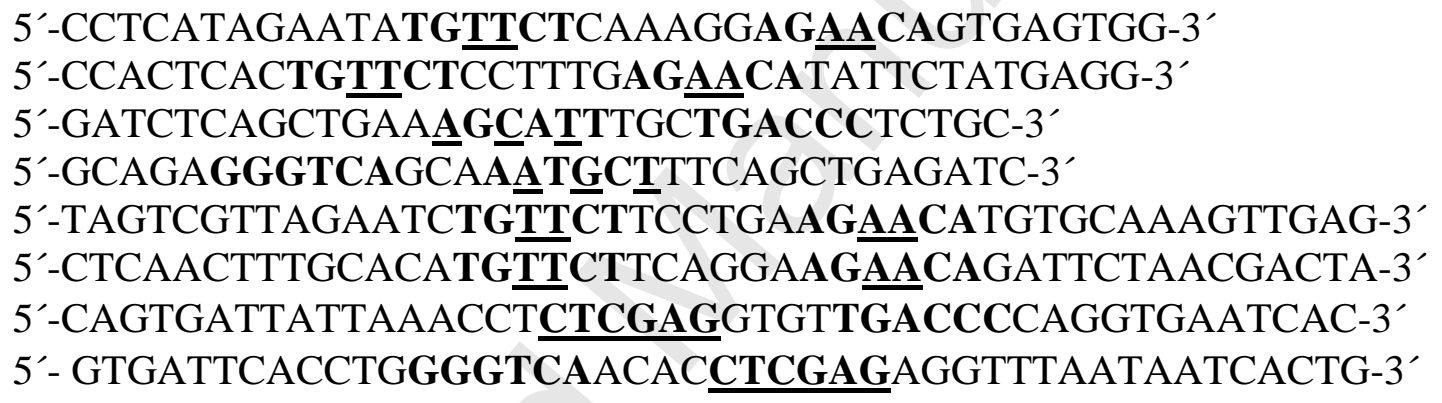

\section{5'- CCTAATAATGTGTTTTGGGGTAA-3'}

5'- TTCAACAAGGATTATGCCAG -3'

5'- CTCAACCTGTCTGCAGTAGTCGT-3'

aplicon 132 bp (ER6-CLEM4)

$$
\begin{aligned}
& \text { 5'- TCAAAGAAACTCATGTCCCAA-3' } \\
& \text { 5'- AGTTCAGCTTGTGATTCACCT-3' } \\
& \text { 5'- CCAGCCTCTCGGTGCCC-3' }
\end{aligned}
$$

aplicon 132 bp (dNR1-DR3), dNR2, eNR3A4 (DR4)

5'- TGATAAGAACCCAGAACCCT-3'

5'- GGTCAGTGAGTGGTGTGTG-3'

5'- GGACTCCCCAGTAACATTGATTG-3' aplicon 102 bp (prER6)

5'-(biotin) ACCTTGTCCTGTGTTGACCCCAGG-3'

5'-(biotin) CCTGGGGTCAACACAGGACAAGGT-3'

5'-(biotin) AGAATCTGAACTTCCTGAAGTTCATGTGCA-3'

5'-(biotin) TGCACATGAACTTCAGGAAGTTCAGATTCT-3'

*Bold bases indicate receptor binding sites and underlined bases were changed to disrupt nuclear hormone receptor binding. 
Table 2. Schematic roles of four major response elements in both basal and ligand-inducible VDR- and PXR- mediated transactivation of the CYP3A4 gene in the tested intestinal and hepatocyte-derived cell lines.

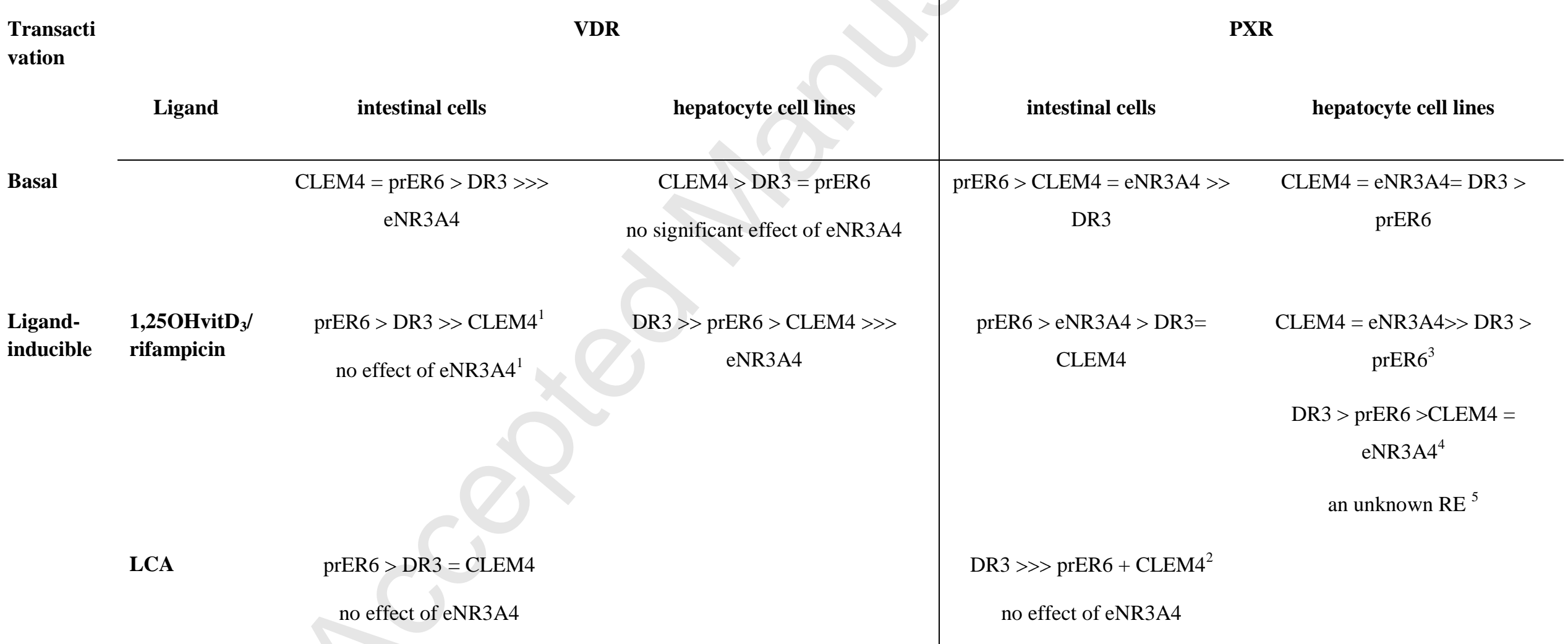

\footnotetext{
${ }^{1}$ the same pattern for LS174T, HCT-8 and HT-29 intestinal cell lines, CLEM4 has a modulatory effect together with pER6 and DR3 sites; for CACO-2 cells- DR3 > prER6>> CLEM4, no effect of eNR3A4

2 cooperation, minimal individual effects of the response elements

${ }^{3}$ In HepG2, relative fold induction is not affected by any response element mutation due to the parallel decrease in basal activation.

4 for Mz-Hep-1 cells

${ }^{5}$ An unknown RE is involved in both HepG2 and MZ-Hep-1.
} 
Figure 1.

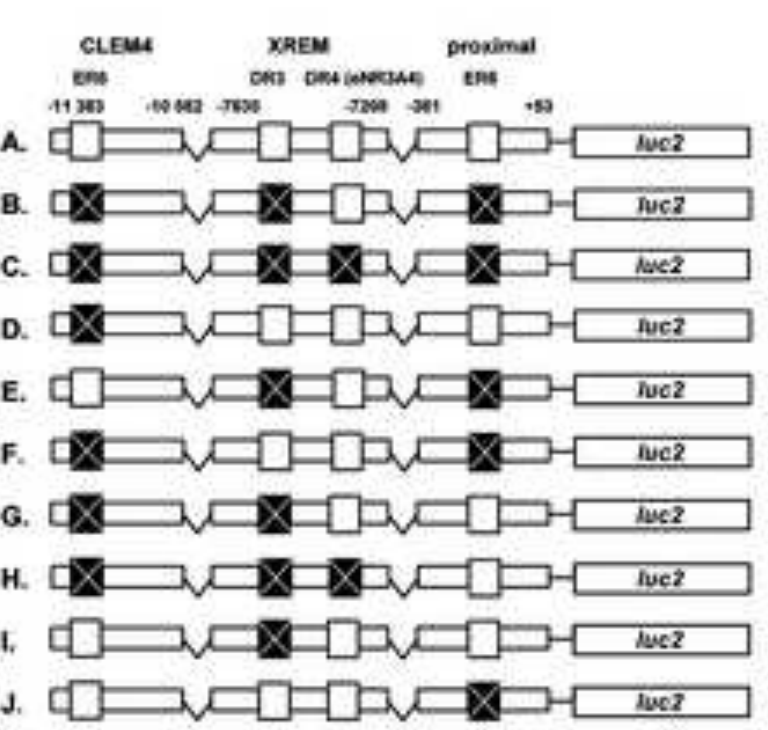

J. $4 \square$ -
A.

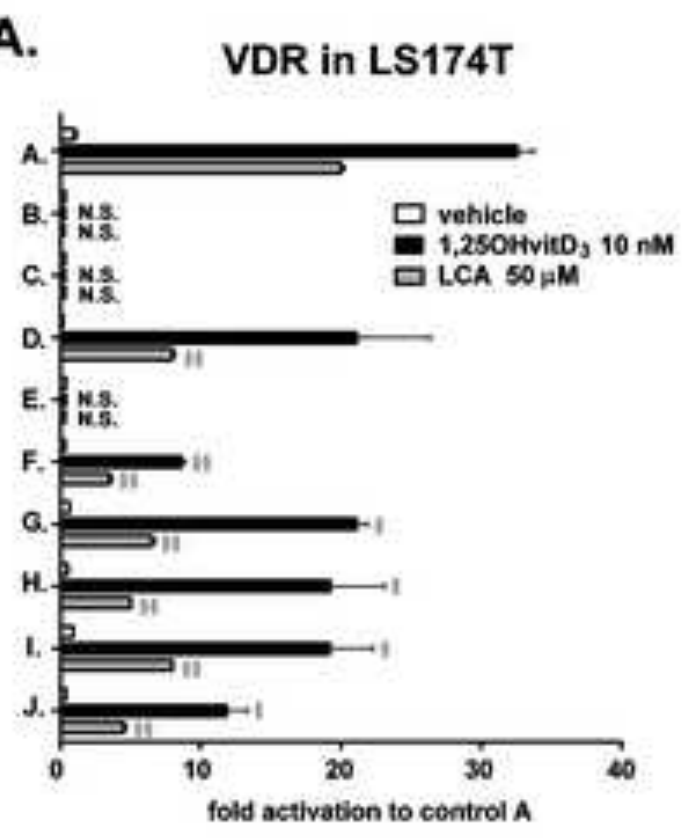

Pavek et al.

B.

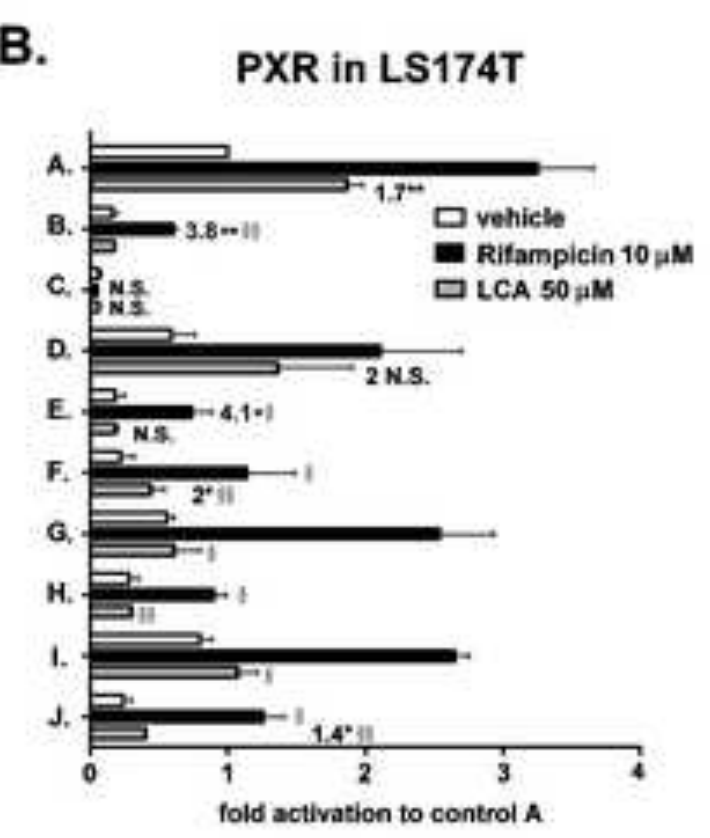


intestinal cell lines

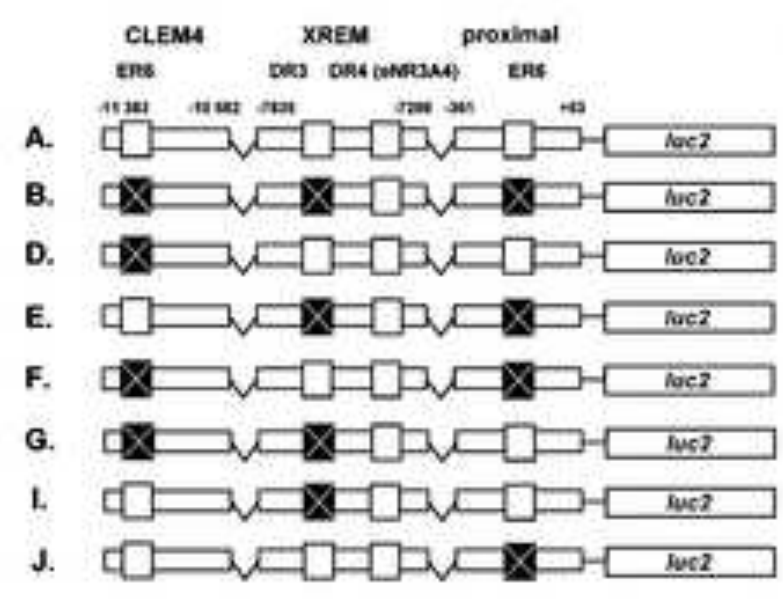

B.

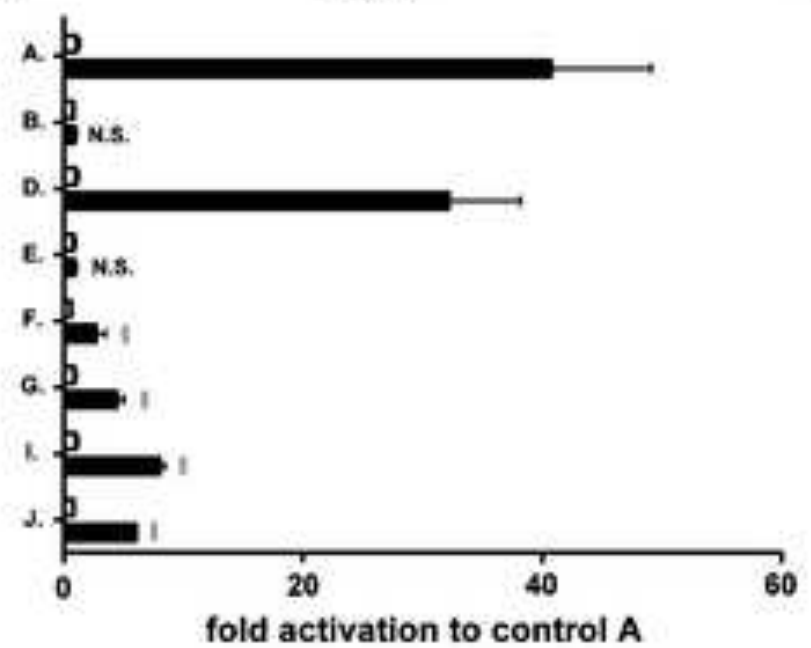

A. HCT-8

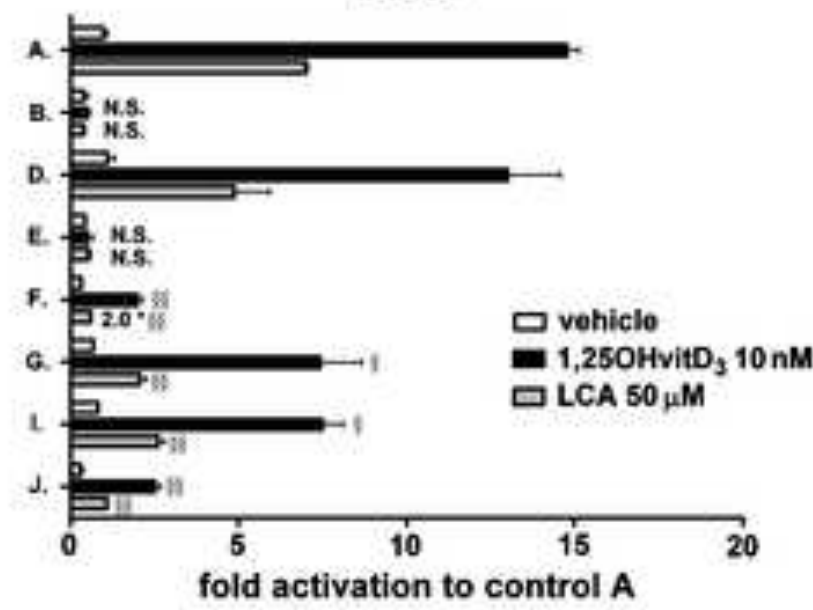

c.

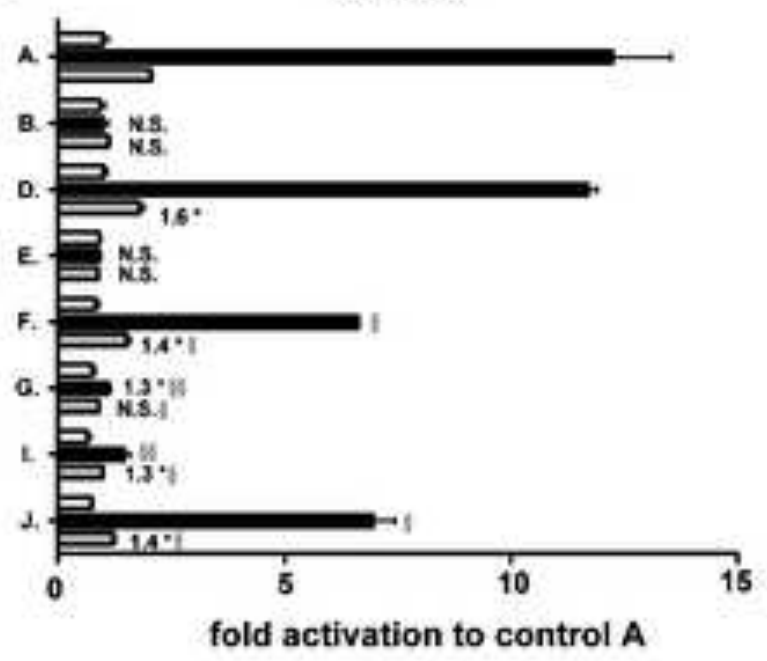


Figure 3.

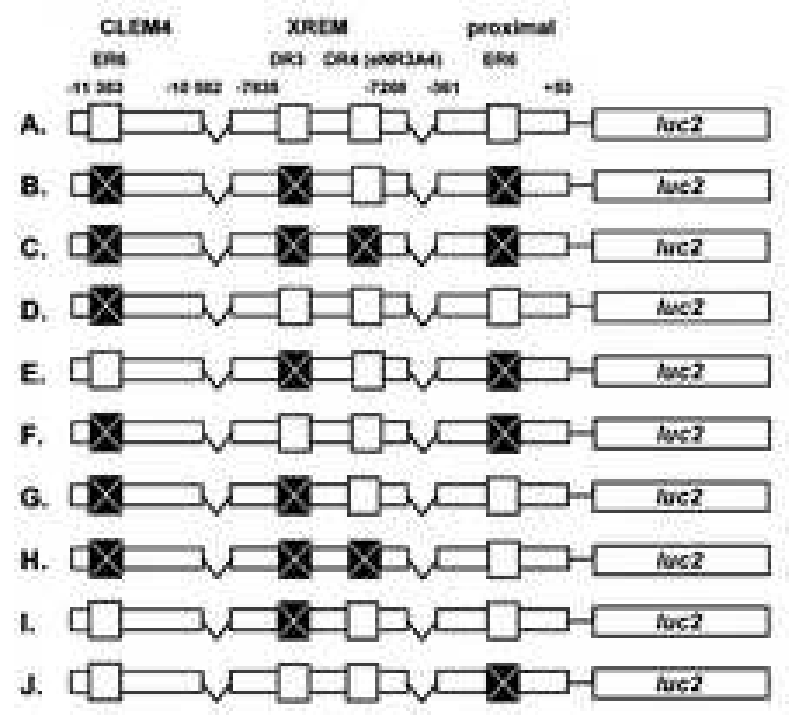

A. VDR HepG2

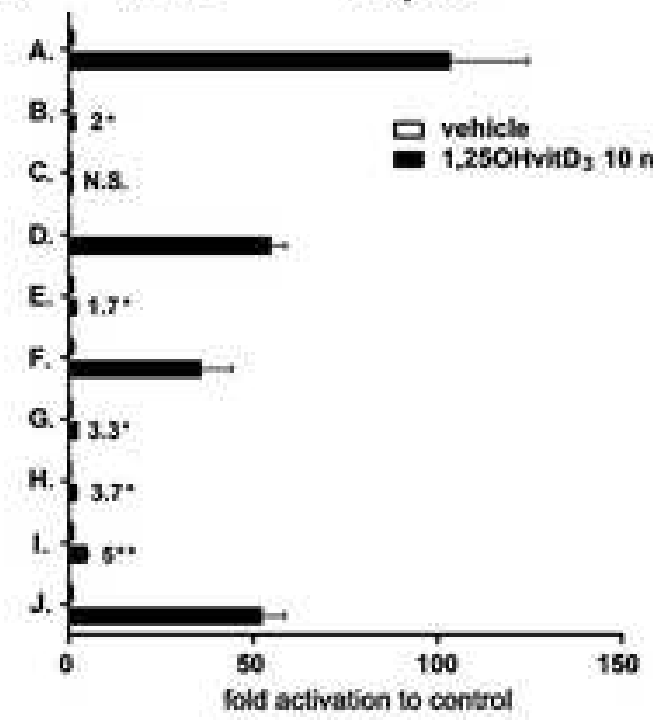

C. VDR MZ-Hep-1

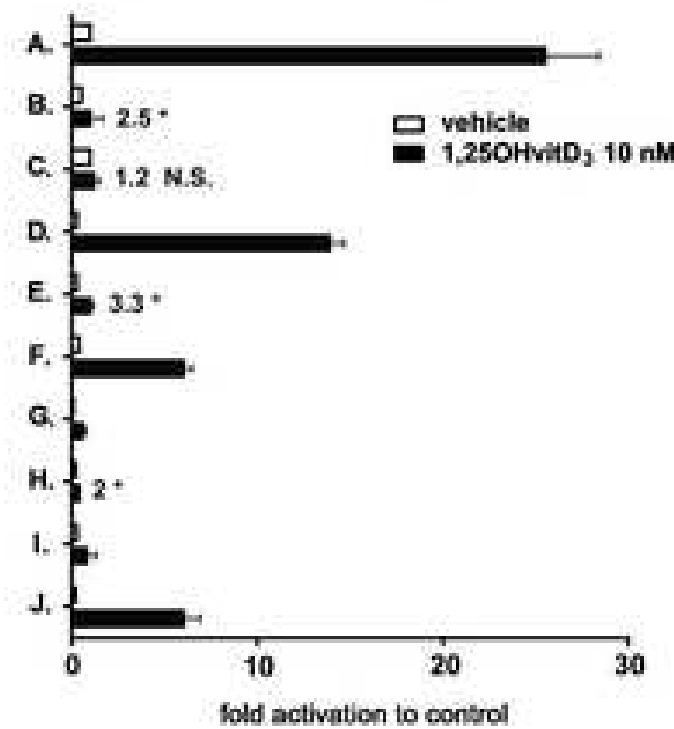

Pavek et al.
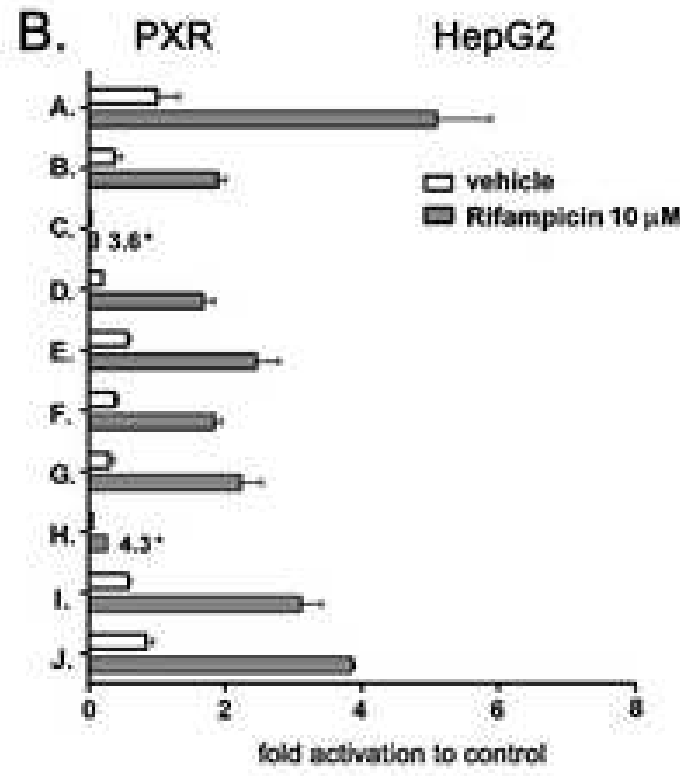

D. PXR MZ-Hep-1

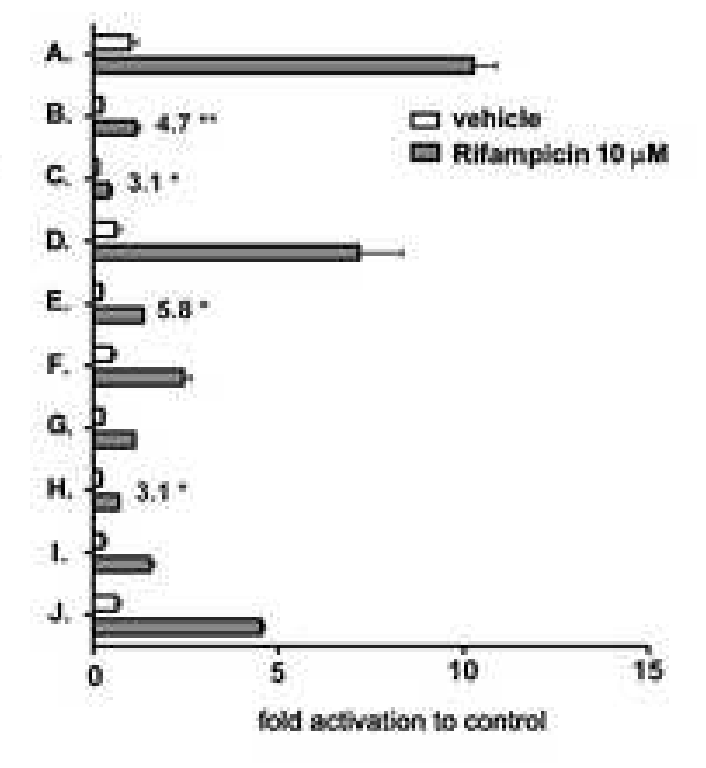

Page 43 of 46

\section{Pavek et al.}

.


Figure 4.

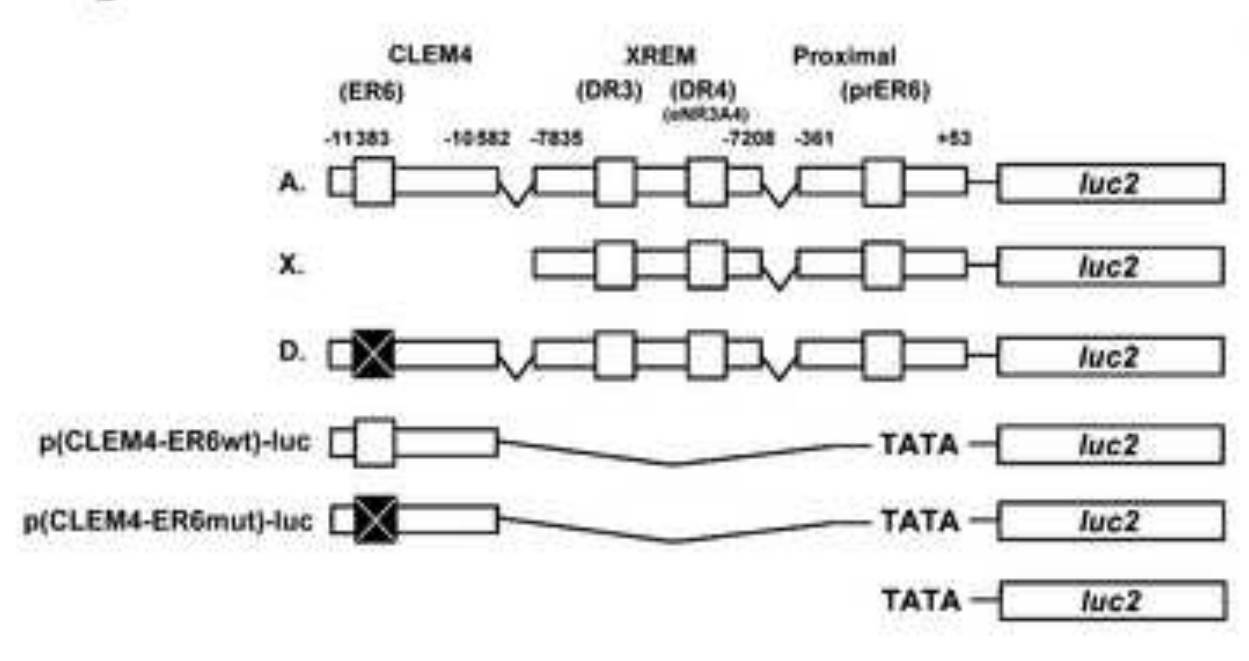

\section{B.}

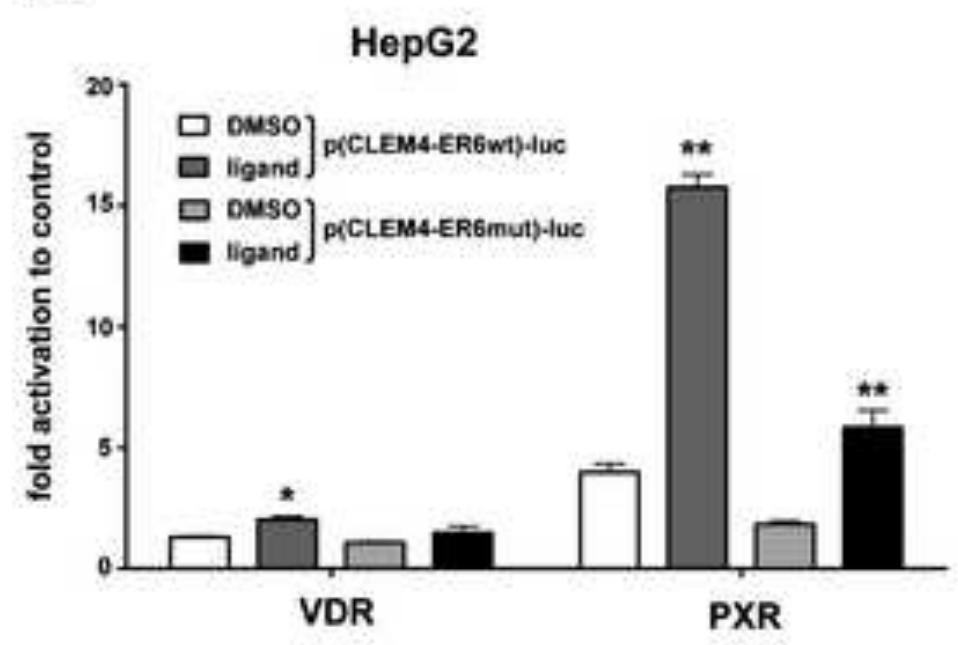

Pavek et al.

A.

LS174T

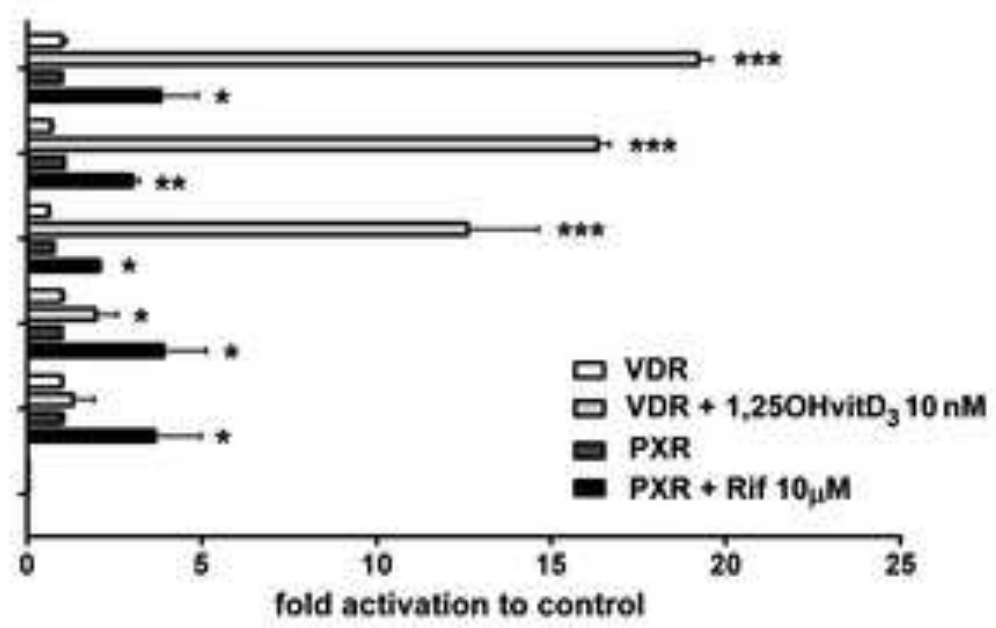

c.

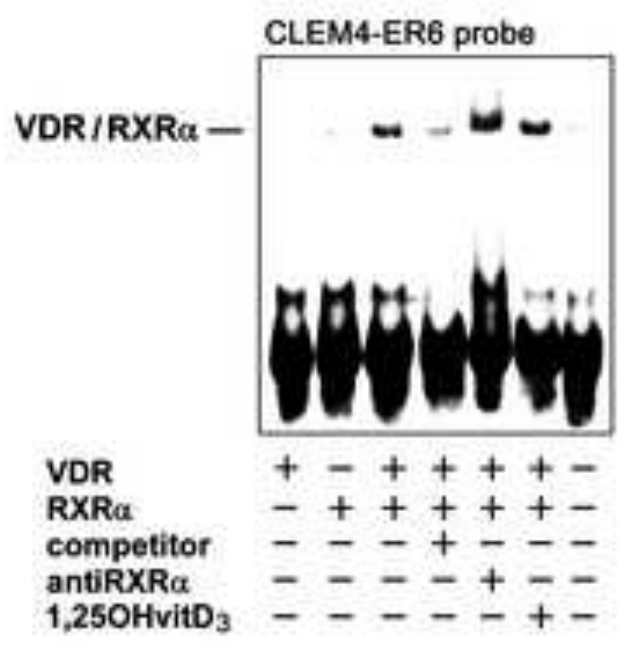


Figure 5.

Pavek et al.

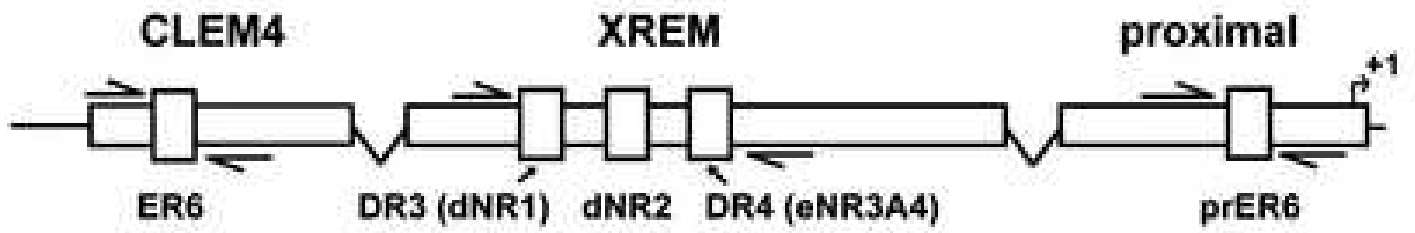

Chip

LS174T

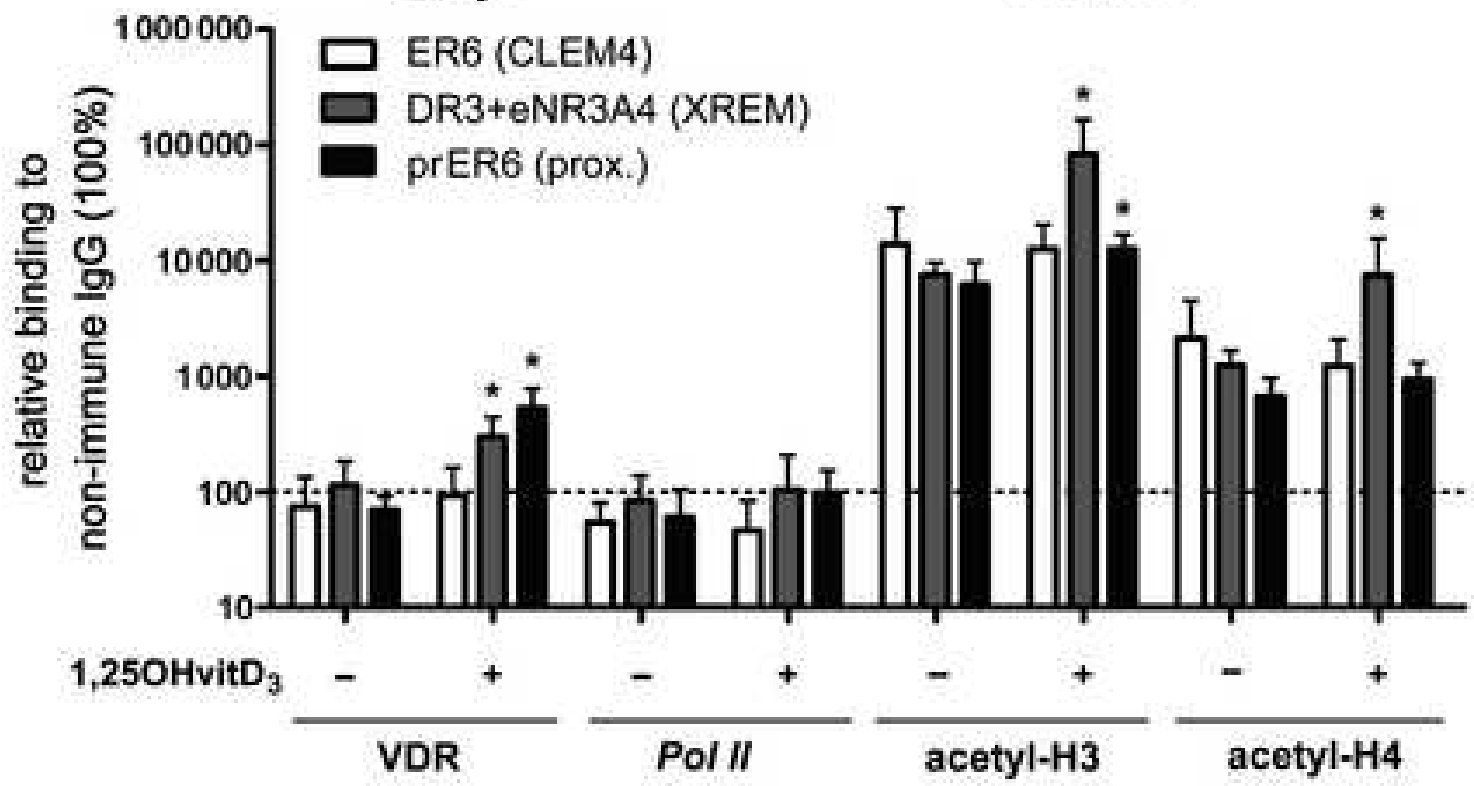


Figure 6.

Pavek et al.

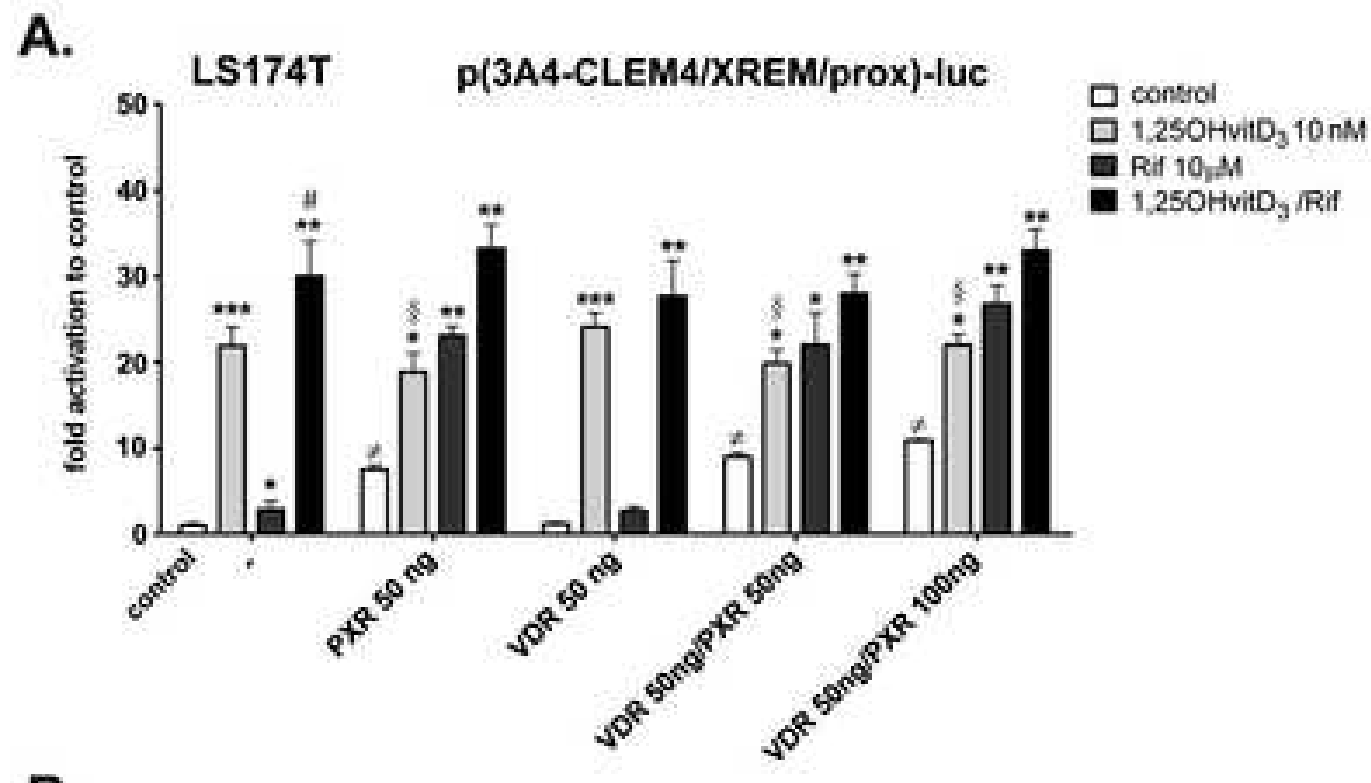

B.

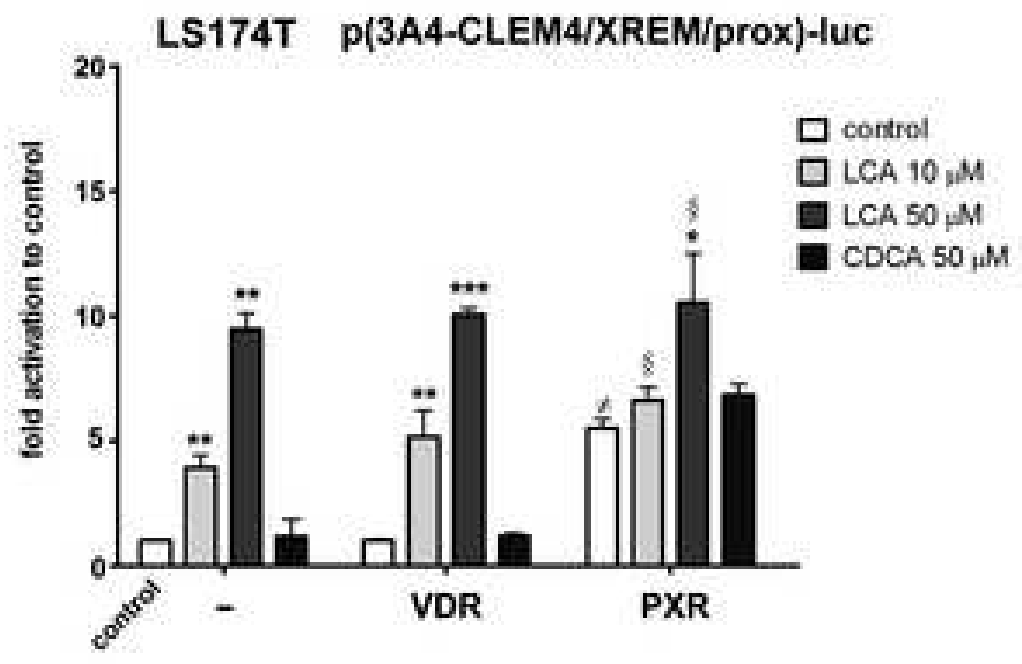

C.

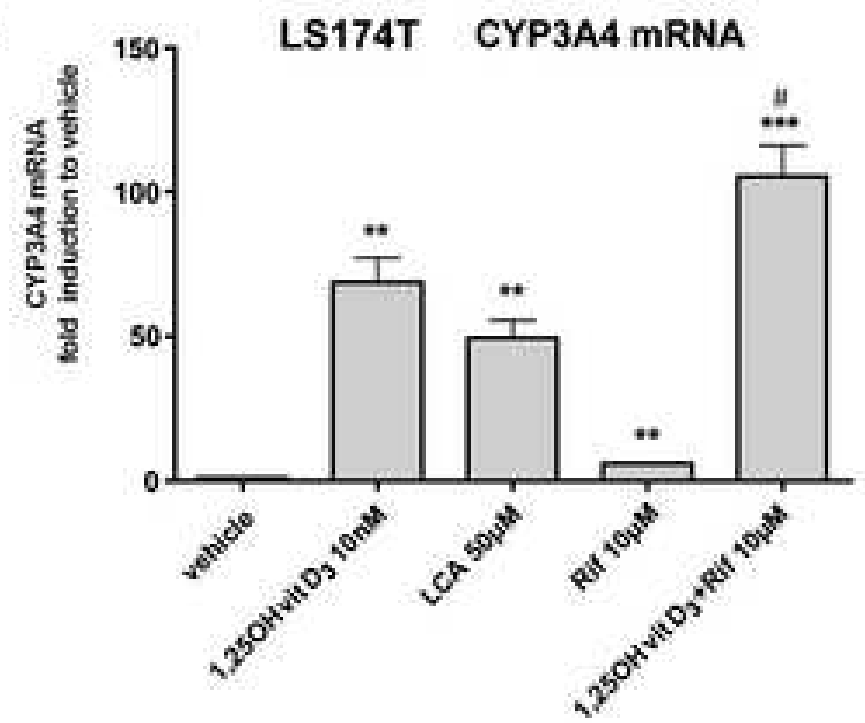

